\title{
Xenon-133 and caesium-137 releases into the atmosphere from the Fukushima Dai-ichi nuclear power plant: determination of the source term, atmospheric dispersion, and deposition
}

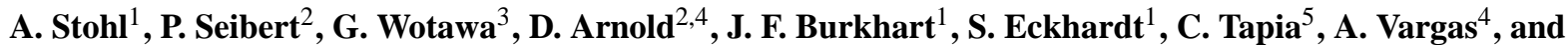 \\ T. J. Yasunari ${ }^{6}$ \\ ${ }^{1}$ NILU - Norwegian Institute for Air Research, Kjeller, Norway \\ ${ }^{2}$ Institute of Meteorology, University of Natural Resources and Life Sciences, Vienna, Austria \\ ${ }^{3}$ Central Institute for Meteorology and Geodynamics, Vienna, Austria \\ ${ }^{4}$ Institute of Energy Technologies (INTE), Technical University of Catalonia (UPC), Barcelona, Spain \\ ${ }^{5}$ Department of Physics and Nucelar Engineering (FEN),Technical University of Catalonia (UPC), Barcelona, Spain \\ ${ }^{6}$ Universities Space Research Association, Goddard Earth Sciences and Technology and Research, Columbia, \\ MD 21044, USA
}

Correspondence to: A. Stohl (ast@ nilu.no)

Received: 8 October 2011 - Published in Atmos. Chem. Phys. Discuss.: 20 October 2011

Revised: 1 February 2012 - Accepted: 23 February 2012 - Published: 1 March 2012

\begin{abstract}
On 11 March 2011, an earthquake occurred about $130 \mathrm{~km}$ off the Pacific coast of Japan's main island Honshu, followed by a large tsunami. The resulting loss of electric power at the Fukushima Dai-ichi nuclear power plant developed into a disaster causing massive release of radioactivity into the atmosphere. In this study, we determine the emissions into the atmosphere of two isotopes, the noble gas xenon-133 $\left({ }^{133} \mathrm{Xe}\right)$ and the aerosol-bound caesium-137 $\left({ }^{137} \mathrm{Cs}\right)$, which have very different release characteristics as well as behavior in the atmosphere. To determine radionuclide emissions as a function of height and time until 20 April, we made a first guess of release rates based on fuel inventories and documented accident events at the site. This first guess was subsequently improved by inverse modeling, which combined it with the results of an atmospheric transport model, FLEXPART, and measurement data from several dozen stations in Japan, North America and other regions. We used both atmospheric activity concentration measurements as well as, for ${ }^{137} \mathrm{Cs}$, measurements of bulk deposition. Regarding ${ }^{133} \mathrm{Xe}$, we find a total release of 15.3 (uncertainty range $12.2-18.3) \mathrm{EBq}$, which is more than twice as high as the total release from Chernobyl and likely the largest radioactive noble gas release in history. The entire noble gas inventory of reactor units 1-3 was set free into the atmosphere between 11 and 15 March 2011. In fact, our release estimate is higher than the entire estimated ${ }^{133} \mathrm{Xe}$ inventory
\end{abstract}

of the Fukushima Dai-ichi nuclear power plant, which we explain with the decay of iodine-133 (half-life of $20.8 \mathrm{~h}$ ) into ${ }^{133} \mathrm{Xe}$. There is strong evidence that the ${ }^{133} \mathrm{Xe}$ release started before the first active venting was made, possibly indicating structural damage to reactor components and/or leaks due to overpressure which would have allowed early release of noble gases. For ${ }^{137} \mathrm{Cs}$, the inversion results give a total emission of $36.6(20.1-53.1) \mathrm{PBq}$, or about $43 \%$ of the estimated Chernobyl emission. Our results indicate that ${ }^{137} \mathrm{Cs}$ emissions peaked on 14-15 March but were generally high from 12 until 19 March, when they suddenly dropped by orders of magnitude at the time when spraying of water on the spentfuel pool of unit 4 started. This indicates that emissions may not have originated only from the damaged reactor cores, but also from the spent-fuel pool of unit 4 . This would also confirm that the spraying was an effective countermeasure. We explore the main dispersion and deposition patterns of the radioactive cloud, both regionally for Japan as well as for the entire Northern Hemisphere. While at first sight it seemed fortunate that westerly winds prevailed most of the time during the accident, a different picture emerges from our detailed analysis. Exactly during and following the period of the strongest ${ }^{137} \mathrm{Cs}$ emissions on 14 and 15 March as well as after another period with strong emissions on 19 March, the radioactive plume was advected over Eastern Honshu Island, where precipitation deposited a large fraction of ${ }^{137} \mathrm{Cs}$ 
on land surfaces. Radioactive clouds reached North America on 15 March and Europe on 22 March. By middle of April, ${ }^{133} \mathrm{Xe}$ was fairly uniformly distributed in the middle latitudes of the entire Northern Hemisphere and was for the first time also measured in the Southern Hemisphere (Darwin station, Australia). In general, simulated and observed concentrations of ${ }^{133} \mathrm{Xe}$ and ${ }^{137} \mathrm{Cs}$ both at Japanese as well as at remote sites were in good quantitative agreement. Altogether, we estimate that $6.4 \mathrm{PBq}$ of ${ }^{137} \mathrm{Cs}$, or $18 \%$ of the total fallout until 20 April, were deposited over Japanese land areas, while most of the rest fell over the North Pacific Ocean. Only $0.7 \mathrm{PBq}$, or $1.9 \%$ of the total fallout were deposited on land areas other than Japan.

\section{Introduction}

On 11 March 2011, an extraordinary magnitude 9.0 earthquake occurred about $130 \mathrm{~km}$ off the Pacific coast of Japan's main island Honshu, at $38.3^{\circ} \mathrm{N}, 142.4^{\circ} \mathrm{E}$, followed by a large tsunami (USGS, 2011). These events caused the loss of many lives and extensive damage. One of the consequences was a station blackout (total loss of AC electric power) at the Fukushima Dai-ichi nuclear power plant (in the following, FD-NPP). The station blackout developed into a disaster leaving four of the six FD-NPP units heavily damaged, and causing a largely unknown but massive discharge of radionuclides into the air and into the ocean.

Measurement data published by the Ministry of Education, Culture, Sports, Science and Technology of Japan (MEXT, 2011) and others (Chino et al., 2011; Yasunari et al., 2011) show that the emissions from FD-NPP caused strongly elevated levels of radioactivity in Fukushima prefecture and other parts of Japan. Enhanced concentrations of airborne radionuclides were in fact measured at many locations all over the Northern Hemisphere (e.g. Bowyer et al., 2011; Masson et al., 2011). Thus, an extensive body of observations documents local, regional and global impacts of the FD-NPP accident. Nevertheless, point measurements alone are by far too sparse to determine the radionuclides' three-dimensional atmospheric distribution and surface deposition, and consequently their effects on the environment; especially because measured concentrations cover many orders of magnitude and cannot be spatially interpolated easily. Given accurate emissions, dispersion models can simulate the atmospheric distribution and deposition of radionuclides providing a more complete picture than the measurements alone. For instance, after the Chernobyl disaster in 1986, models have been used to study the distribution of radionuclides across Europe (e.g., Hass et al., 1990; Brandt et al., 2002). Morino et al. (2011) have presented a regional model analysis of the FD-NPP accident. The simulations need to be compared carefully with measurement data since inaccuracies in the meteorological input data or in the model parameterizations (e.g., of wet and dry deposition, or turbulence) can lead to erroneous simulations. However, the single largest source of error for model predictions is the source term, i.e., the rate of emissions into the atmosphere from the accident site as a function of time and height. Therefore, efforts must be made to provide an adequate source term to models before they can produce reliable results. This is particularly true for nuclear accidents where release rates can vary by orders of magnitude on timescales of synoptic variability, which determines the areas affected by the plume.

Bottom-up estimates of the source term based on understanding and modeling of processes at the accident site are typically of limited accuracy, especially with respect to the timing of the releases. For instance, the time variation of the emissions from Chernobyl is still uncertain (Devell et al., 1995; NEA, 2002). At the time of writing, the most comprehensive information source on the events in the FD-NPP and its environmental consequences is a report released by the Government of Japan in June 2011 (Nuclear Emergency Response Headquarters, 2011) (hereafter, referred to as the Report) and its subsequent updates. Unless otherwise mentioned, technical information used in this paper is based on this document. Although this report contains estimates of the amounts of radioactivity set free into the atmosphere for certain key nuclides, these data are not reliable. The releases did not occur through defined pathways and were not metered. Release estimates could and can only be obtained by either simulating the accident sequences with dedicated severe nuclear accident simulation codes like MELCOR (Gauntt et al., 2001), or by some kind of inverse modeling based on atmospheric transport modeling and environmental monitoring data. Results of both approaches are presented in the Report.

A viable approach for determining the source term is to combine radionuclide measurement data and atmospheric dispersion models. By optimizing the agreement between the model calculations with the measurement data, an improved source term can be obtained. This top-down approach is called inverse modeling and was used early to make estimates of the Chernobyl source term (Gudiksen et al., 1989). More recently, inverse modeling has been used by Davoine and Bocquet (2007) to derive the Chernobyl emissions both as a function of time and height, and by Winiarek et al. (2012) to estimate lower bounds for the FD-NPP emissions. Advanced inverse modeling schemes also use a priori information on emissions based on nuclear accident simulations and understanding of events at the accident site. Similar inverse model systems have been used for related problems. Considerable work has been done, for instance, to determine greenhouse gas emissions into the atmosphere (Hartley and Prinn, 1993; Mahowald et al., 1997; Stohl et al., 2009).

The core author team of this article has previously developed an inverse modeling methodology for cases such as volcanic eruptions and greenhouse gas emissions. Our most recent application, reconstructing the time- and heightdependent ash emissions from the Eyjafjallajökull volcanic 
Table 1. Overview of the reactor blocks (units) at the FD-NPP according to Table "Generation Facilities at the Fukushima Dai-ichi NPS" (not numbered, on p. 46) and Table IV-3-1 in Nuclear Emergency Response Headquarters (2011).

\begin{tabular}{lllllll}
\hline & Unit 1 & Unit 2 & Unit 3 & Unit 4 & Unit 5 & Unit 6 \\
\hline Electric power output (MW) & 460 & 784 & 784 & 784 & 784 & 1100 \\
Begin commercial operation & 1971 & 1974 & 1976 & 1978 & 1978 & 1979 \\
Reactor model & BWR 3 & BWR 4 & BWR 4 & BWR 4 & BWR 5 & BWR 5 \\
Containment type & Mark-1 & Mark-1 & Mark-1 & Mark-1 & Mark-1 & Mark-2 \\
Operating/time of shut-down & operating & operating & operating & $2010-11-29$ & $2011-01-02$ & $2010-08-13$ \\
Number of fuel assemblies in core & 400 & 548 & 548 & 0 & - & - \\
Number of fuel assemblies in pond & 392 & 615 & 566 & 1535 & 994 & 940 \\
\hline
\end{tabular}

eruption in spring 2010 (Stohl et al., 2011a), is closely related to the problem posed by the Fukushima nuclear accident. In both cases we have a point source with unknown vertical and temporal distribution of the emissions. However, while for volcanic ash millions of satellite observations were made, observations of radionuclides are available only as point measurements at certain monitoring sites, and with a coarse temporal resolution of typically $24 \mathrm{~h}$. Even though we have collected measurements from a large set of stations in Japan and throughout the entire Northern Hemisphere, the total number of available observations is only of the order of one thousand. While this makes the problem much less well conditioned than for the volcanic ash scenario, still much can be learned about the FD-NPP source term by using the top-down inverse method, especially if the inversion can be guided by a bottom-up a priori (first guess) estimate based on carefully compiled information. In this paper, we determine the emissions of two important radionuclides, the noble gas xenon-133 ( ${ }^{133} \mathrm{Xe}$, lifetime of 5.25 days) and the aerosol-bound caesium-137 ( ${ }^{137} \mathrm{Cs}$, lifetime of $30 \mathrm{yr}$ ), which have very different release and transport characteristics, and for which measurement data are relatively abundant. We then use the model to simulate the atmospheric dispersion and, for ${ }^{137} \mathrm{Cs}$, the deposition over Japan and throughout the Northern Hemisphere.

The paper is structured as follows: In Sect. 2, we give an overview of the accident events that had led to the disaster and how knowledge of these events was used to determine a priori emissions. In Sect. 3 we present the measurement data and model used and describe the inversion method. In Sect. 4, we report our emission estimates, provide a comparison of measured and modeled concentrations and deposition amounts, and present the simulated concentration and deposition fields and put them into meteorological context. In Sect. 5, we draw conclusions from our work.

\section{Accident events and first-guess emissions}

Fukushima is a prefecture in the East of the Japanese island Honshu. On its eastern coast, two nuclear power plant complexes are located, called Fukushima-I or Fukushima Dai- ichi, and Fukushima-II or Fukushima Dai-ni ${ }^{1}$, operated by the company TEPCO. Fukushima Dai-ichi (FD-NPP), where the severe accidents occurred, consists of six boiling water reactors lined up directly along the shore. The reactor blocks are built in pairs. Table 1 gives an overview of the units. When the earthquake occurred, units 4 to 6 had been already shut down for several months for maintenance, while units 1 to 3 were under operation at their rated power.

Nuclear reactors also house pools for initial storage of spent fuel assemblies. In the boiling water reactor (BWR) design, this pool is located outside the containment near the top of the reactor building. Table 1 indicates the amount of fuel in these ponds. Even considering that shorter lived nuclides have decayed, it is obvious that these ponds present a significant inventory of radioactivity. Furthermore, there is a larger common spent fuel pool at the site, on ground level. Spent fuel is transferred to this pool after at least 19 months, but the decay heat is large enough to still require active cooling. This pond contained 6375 fuel assemblies.

The earthquake triggered the automatic shutdown of the chain reaction in the units 1 to 3 at 05:46 UTC (that is 14:46 Japan Standard Time) on 11 March. Outside power supply was lost and the emergency diesel generators started up. However, when the tsunami arrived 50 minutes later, it inundated the sites of the reactors and their auxiliary buildings and caused the total loss of AC power, except for one of the three diesel generators of unit 6 . Although at different rates, cooling of the reactor cores was lost, water levels in the reactor pressure vessels could not be maintained, and in all three units that had been under operation, the cores degraded and, as has been reported, partially (or maybe even completely) melted. The hydrogen produced in this process caused major explosions which massively damaged the upper parts of the reactor buildings of units 1 and 3. Damage to the upper parts of the reactor building could be prevented in unit 2 , however, a hydrogen explosion there presumably damaged the suppression chamber.

Cooling was lost as well for the spent fuel ponds, leading to heating up of the water and raising concerns about fuel

\footnotetext{
1 ichi means 1 , ni means 2
} 
Table 2. Estimated inventories of the radionuclide sources (reactor cores and spent fuel pools [SFP]) in units 1 to 4 . Activities refer to the time of the earthquake, when the chain reaction in the operating reactors was stopped. For estimating the core inventories, we used an average burnup of $30000 \mathrm{MWd} / \mathrm{tU}$ and $68 \mathrm{tU}$ for unit 1, and $23000 \mathrm{MWd} / \mathrm{tU}$ and $94 \mathrm{tU}$ for units 2 and 3. $40000 \mathrm{MWd} / \mathrm{tU}$ and 68 and $94 \mathrm{tU}$ was used for the SFP inventories.

\begin{tabular}{lrr}
\hline Source & ${ }^{133} \mathrm{Xe}(\mathrm{Bq})$ & ${ }^{137} \mathrm{Cs}(\mathrm{Bq})$ \\
\hline Core unit 1 & $2.72 \times 10^{18}$ & $2.40 \times 10^{17}$ \\
Core unit 2 & $4.85 \times 10^{18}$ & $2.59 \times 10^{17}$ \\
Core unit 3 & $4.85 \times 10^{18}$ & $2.59 \times 10^{17}$ \\
\hline Total cores & $1.24 \times 10^{19}$ & $7.58 \times 10^{17}$ \\
\hline SFP unit 1 & $1.50 \times 10^{12}$ & $2.21 \times 10^{17}$ \\
SFP unit 2 & $2.59 \times 10^{12}$ & $4.49 \times 10^{17}$ \\
SFP unit 3 & $2.59 \times 10^{12}$ & $3.96 \times 10^{17}$ \\
SFP unit 4 & $1.04 \times 10^{13}$ & $1.11 \times 10^{18}$ \\
\hline Total SFPs & $1.71 \times 10^{13}$ & $2.18 \times 10^{18}$ \\
\hline Grand total & $1.24 \times 10^{19}$ & $2.94 \times 10^{18}$ \\
\hline Total cores/grand total & 1.0 & 0.258 \\
\hline
\end{tabular}

rods also becoming uncovererd there. The information concerning these ponds and possible releases from them is much less clear. However, it is obvious that the most dangerous situation was in the pond of unit 4 , into which the whole core had been unloaded for maintenance work in the reactor. The decay heat for this pool was about $2 \mathrm{MW}$. A massive hydrogen explosion occurred there which may have been caused by degraded fuel from this pond, or, as has been suggested by TEPCO, hydrogen may have migrated from unit 3 through pipeworks connecting this pair of units.

In the appendix, we provide a more detailed overview of the events happening at each one of the units 1-4. Fortunately, due to the maintenance outage and the survival of one diesel generator, it seems that unit 5 and 6 reactor cores as well as spent fuel ponds have not suffered major fuel damage and did not produce large emissions. Therefore, they are not included in the further considerations.

\subsection{First-guess emissions}

In order to estimate the radionuclide emissions with a bottom-up approach, the respective nuclide inventories per reactor unit and for the spent-fuel ponds must be known. Based on the information in the Report on the number of fuel assemblies and assuming a four-year fuel cycle, burn-up calculations have been performed with the ORIGEN code (Oak Ridge National Laboratory, 2005). Results for the relevant nuclides are reported in Table 2. There are $7.58 \times 10^{17} \mathrm{~Bq}$ (758 PBq) of ${ }^{137} \mathrm{Cs}$ in the three reactor cores, while the spentfuel pools of units 1-4 contain almost $2200 \mathrm{PBq}$. Thus, only
$26 \%$ of the ${ }^{137} \mathrm{Cs}$ in the affected units is in the reactor cores. However, due to the higher energy density especially shortly after the stop of the chain reaction, it is more easily set free into the environment from the cores. The pool of unit 4 contains about half of the total spent-fuel pool ${ }^{137} \mathrm{Cs}$ inventory. Because of the short half-life of ${ }^{133} \mathrm{Xe}$, its inventory in the spent fuel can be neglected compared to the reactor cores.

In terms of releases, early estimates by the Austrian Central Institute for Meteorology and Geodynamics (2011) and the French Institut de Radioprotection et de Surete Nucleaire (2011) indicated significant emissions during the first phase of the accident. On 22 March, Central Institute for Meteorology and Geodynamics (2011) published a source estimate of about $66 \mathrm{PBq}{ }^{137} \mathrm{Cs}$ (see also Nature News Blog, 2011). The estimate was valid for the first four release days (12-15 March) and was based on forward transport modeling and comparison of results with measurements at stations of the Comprehensive Nuclear-Test-Ban Treaty Organization (CTBTO). On the same day, Institut de Radioprotection et de Surete Nucleaire (2011) reported an estimated emission of $30 \mathrm{PBq}$ caesium between 12 and 22 March, based on diagnostics of the state of the reactors 1-3 of FD-NPP, combined with dispersion model results. Later on, estimates made by the Japanese authorities suggested complete release of the entire noble gas inventory (about $12 \mathrm{EBq}$ for ${ }^{133} \mathrm{Xe}$ ) and around $1-2 \%$ of the caesium contained in the reactor cores of units 1-3, about 10-15 PBq (Table 3). Given the massive fuel damage that has been reported for all three cores, there is little doubt that the noble gas release fraction should be practically $100 \%$. The more interesting aspects here are the temporal and vertical distribution of the release, which determine atmospheric transport patterns, as well as how much ${ }^{137} \mathrm{Cs}$ was set free into the atmosphere. Our first guess has been guided by the Japanese assessments and thus its total magnitude corresponds to: $100 \%$ of ${ }^{133} \mathrm{Xe}(12.4 \mathrm{EBq})$ and about $1.7 \%$ (12.6 PBq) of ${ }^{137} \mathrm{Cs}$. However, we add another $8.9 \mathrm{PBq}{ }^{137} \mathrm{Cs}$ from the spent fuel pool of unit 4. Releases from the other spent fuel pools are assumed to be minor compared, on one hand, to the releases from the respective reactor cores, and on the other hand to the unit 4 pool, especially considering the uncertainties assumed which provide for potential emissions from pools 1 to 3 . Note that the emission from pool 4 is assigned sufficient uncertainty as to allow its suppression by the inversion if it were not consistent with the observations.

In order to produce a set of first-guess (a priori) emissions as needed for the inversion, the total amount of radionuclides emitted must be disaggregated into a temporal sequence. For this, we used all available information, such as observed radiation increases, pressure build-up and decay in various reactor compartments, information on relief valves opened or closed, and the hydrogen explosions, together with the temporal shape from the MELCOR (Gauntt et al., 2001) simulations provided in the Report. In addition, on-site gamma dose 

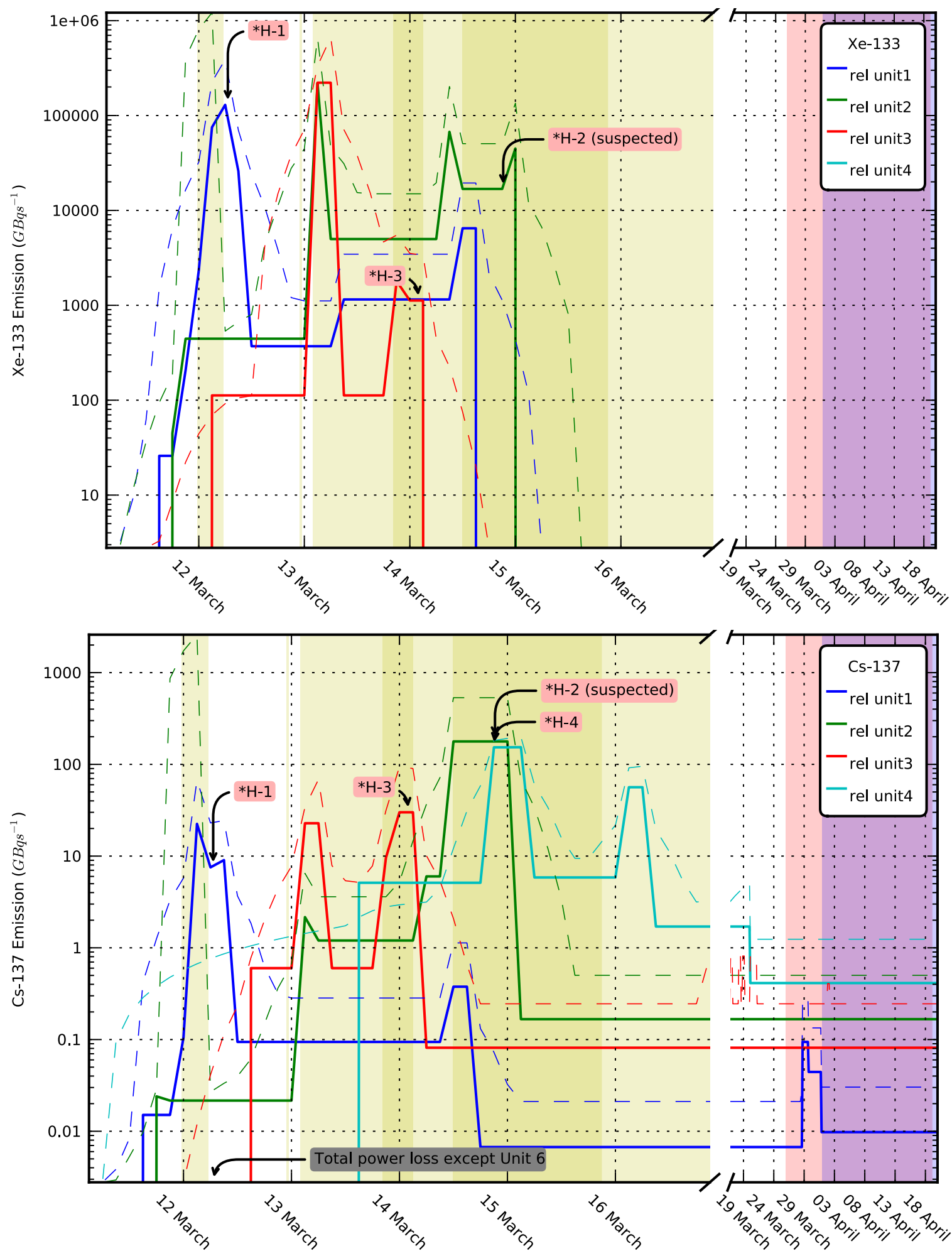

Fig. 1. First guess emissions as a function of time for the four different reactor units, for ${ }^{133} \mathrm{Xe}$ (top panel) and for ${ }^{137} \mathrm{Cs}$ (bottom panel). Emissions are drawn with colored solid bold lines (blue, unit 1; green, unit 2; red, unit 3; sky blue, unit 4), and emission uncertainties are drawn with correspondingly colored thin dashed lines. Major hydrogen explosions are indicated by $* \mathrm{H}-\mathrm{U}$, where $\mathrm{U}$ is the unit number. Periods of known venting are shaded in yellow. A period of increased observed temperature is shaded in red, and overlaps a period of increased pressure (shaded in blue). Notice that the time axis is stretched before 18 March. 
rate monitoring data published by TEPCO in their bulletins ${ }^{2}$ have been used. This latter data source is only a very rough guidance for two reasons. Firstly, the published data refer to different locations on the reactor site for different time periods (and published documents do not explain why monitoring posts were changed), and secondly, complex interaction between wind conditions, release locations and monitoring locations must be expected but cannot be resolved by us due to a lack of detailed data.

Figure 1 shows the time variation of the derived first-guess emissions and their assumed uncertainties separately for each reactor unit and relates them to certain events (see the appendix for detailed description). The first guess uncertainties are much higher than the emissions, giving the inversion enough freedom to change the a priori emissions substantially. Comparing ${ }^{133} \mathrm{Xe}$ and ${ }^{137} \mathrm{Cs}$ emissions, the ${ }^{133} \mathrm{Xe}$ emissions occur over much shorter periods of time, as most of the noble gas inventory is assumed to be injected into the atmosphere by the first venting event at each unit. Emissions of ${ }^{137} \mathrm{Cs}$ are more influenced by the hydrogen explosions and generally occur over a more extended time period, while only a small part of the inventory is released.

For the inversion, it is not possible to consider the emissions for each unit separately and, thus, all emissions were summed. Uncertainties are probably not strictly additive, but were also summed. The emissions from spent-fuel pools and reactor cores could in principle be disentangled using nuclide ratios or joint inversions of several nuclides, but this is out of the scope of this paper. However, in the interpretation of the results, we will try to partly relate changes of the emissions to certain events at individual reactor units. All in all, the resulting first guess is obviously a largely subjective product with major uncertainty margins.

\subsection{Release heights}

Atmospheric transport of emitted nuclides depends on the height of the source, due to vertical wind shear and also turbulence conditions. Considering that the present problem is rather weakly constrained, releases are divided into three layers only: 0-50 m, 50-300 m, and 300-1000 m above ground level. The a priori source term needs to be divided between these three layers. The height of the reactor buildings of FDNPP is $40 \mathrm{~m}$, so any leakages through wall or roof openings would fall into the first emission layer. Then, each pair of units has an exhaust stack which emits into the second layer. Some of the venting may have occurred through these stacks. Also, the effluents are hot and thus there can be thermal plume rise, contributing to emissions into the second layer. The third layer is thought to be involved only for the period of explosions. Thus, the initial releases were divided

\footnotetext{
${ }^{2}$ kindly made available in a consistent spreadsheet by M. Takigawa from the Japan Agency for Marine-Earth Science and Technology
}

between first and second layer in a ratio 70:30, then in those units where explosions occurred, after the explosion the ratio was set to 50:50. During the explosion in unit 1, $20 \%$ were assumed to be emitted into the third layer. The unit 2 explosion did not produce building damage and is not considered to have increased the effective release height. The unit 3 explosion was much more powerful, and movies show that material is ejected high up into the atmosphere, thus $70 \%$ of the emissions were placed into the third layer for the corresponding $3 \mathrm{~h}$ interval. As for the unit 4 explosion, it was assumed that $10 \%$ went into the third layer.

\section{Methods}

\subsection{Measurement data}

We collected measurements of atmospheric activity concentrations from a variety of sources, as listed in Tables 4 and 5, which also report the total number of samples available for each station during the period of our study. Measurements of atmospheric activity concentrations of both ${ }^{133} \mathrm{Xe}$ and ${ }^{137} \mathrm{Cs}$ were available from CTBTO stations. The Comprehensive Nuclear-Test-Ban Treaty (CTBT) foresees a global ban of all nuclear explosions. To verify compliance with the CTBT, a global international monitoring system with four different measurement technologies is currently being built up, namely for seismic (170 stations), hydroacoustic (11 stations), infrasound (60 stations) and radionuclide (80 stations) monitoring (Hoffmann et al., 2000). As far as the radionuclide monitoring subsystem is concerned, 60 particulate matter monitoring stations are currently delivering data to the International Data Centre of the Preparatory Commission for the CTBTO in Vienna. The stations are all equipped with high-volume aerosol samplers. About $20000 \mathrm{~m}^{3}$ of air is blown through a filter, collecting particulate radionuclides. Gases are not retained in the filters. The collection period is $24 \mathrm{~h}$. The different radionuclides are measured with high-resolution germanium detectors (Schulze et al., 2000; Medici, 2001). The minimum detectable activity concentration of ${ }^{137} \mathrm{Cs}$ is $1 \mu \mathrm{Bq} \mathrm{m}{ }^{-3}$, which is about three orders of magnitude lower than for measurements within typical national radiation monitoring networks.

As part of CTBT treaty monitoring, half of the radionuclide stations shall additionally be equipped with xenon detectors. During the International Noble Gas Experiment (INGE), noble gas measurement systems have been set up worldwide (Wernsberger and Schlosser, 2004; Saey and de Geer, 2005). Currently, about 25 stations are delivering data to CTBTO. The radioxenon isotopes measured are ${ }^{131 m} \mathrm{Xe}$, ${ }^{133 m} \mathrm{Xe},{ }^{133} \mathrm{Xe}$ and ${ }^{135} \mathrm{Xe}$, with half-lives of 11.93 days, 2.19 days, 5.25 days and $9.14 \mathrm{~h}$, respectively. The most prevalent and important isotope is ${ }^{133} \mathrm{Xe}$, which is measured with an accuracy of about $0.1 \mathrm{mBq} \mathrm{m}^{-3}$. The typical global distribution of this isotope is described by Wotawa et al. (2010). The 
Table 3. Release fractions and estimated released activities from various sources, including the first guess (FG) estimate used in this work and our best a posteriori estimate. "Report Att. IV-2" refers to MELCOR (Gauntt et al., 2001) simulation results as reported in Table 5 of Attachment IV-2 of the Report. ZAMG refers to the estimate by Central Institute for Meteorology and Geodynamics (2011) for the first four days of the event. ISRN lists the estimate of Institut de Radioprotection et de Surete Nucleaire (2011) for 12-22 March 2011.

\begin{tabular}{lrrrr}
\hline Source & ${ }^{133} \mathrm{Xe}(\%)$ & ${ }^{133} \mathrm{Xe}(\mathrm{EBq})$ & ${ }^{137} \mathrm{Cs}(\%)$ & ${ }^{137} \mathrm{Cs}(\mathrm{PBq})$ \\
\hline Report Att. IV-2 & 97.3 & 12.2 & 1.7 & 16.4 \\
Report Att. VI & 97.3 & 12.2 & 0.8 & 7.5 \\
SPEEDI (Att. VI-1) & - & - & 1.4 & 13.0 \\
ZAMG & - & - & - & 66.0 \\
ISRN & - & - & - & 30.0 \\
\hline FG core 1 & 100 & 2.7 & 0.3 & 0.7 \\
FG core 2 & 100 & 4.8 & 4.0 & 10.4 \\
FG core 3 & 100 & 4.8 & 0.6 & 1.6 \\
\hline FG cores 1-3 & 100 & 12.4 & 1.7 & 12.6 \\
FG SFP 4 & - & - & 0.8 & 8.9 \\
\hline FG total & 100 & 12.4 & 1.2 & 21.5 \\
A posteriori & 100 & 15.3 & 2.0 & 36.6 \\
\hline
\end{tabular}

Table 4. List of stations used for the ${ }^{133}$ Xe inversions, sorted by longitude. Num gives the number of valid observations used for the inversion.

\begin{tabular}{lrrrl}
\hline Station name & Longitude & Latitude & Num & Data source \\
\hline Wake Island & 166.6 & 19.3 & 40 & CTBTO \\
Oahu & -158.0 & 21.5 & 79 & CTBTO \\
Sidney & -123.4 & 48.7 & 38 & I. Hoffman, personal \\
& & & & communication (2011) \\
Richland & -119.3 & 46.3 & 72 & Bowyer et al. (2011) \\
Yellowknife & -114.5 & 62.5 & 33 & CTBTO \\
Ashland & -99.8 & 37.2 & 79 & CTBTO \\
Panama City & -79.5 & 9.0 & 14 & CTBTO \\
Charlottesville & -78.4 & 38.0 & 76 & CTBTO \\
Ottawa & -75.7 & 45.4 & 27 & CTBTO \\
St. John's & -52.7 & 47.6 & 38 & CTBTO \\
Schauinsland & 7.9 & 47.9 & 39 & CTBTO \\
Spitsbergen & 15.4 & 78.2 & 79 & CTBTO \\
Stockholm & 17.6 & 59.2 & 79 & CTBTO \\
Ulan-Bator & 106.3 & 47.9 & 37 & CTBTO \\
Guangzhou & 113.3 & 23.0 & 39 & CTBTO \\
Darwin & 130.9 & -12.4 & 78 & CTBTO \\
Ussuriysk & 132.0 & 44.2 & 59 & CTBTO \\
\hline Total & & & 906 & \\
\hline
\end{tabular}

collection period of the xenon samples is typically $12 \mathrm{~h}$. All measured radionuclide concentrations were decay-corrected for the sampling period to the end of the sampling interval and converted from activity per norm cubic meter at standard temperature and pressure $(273.15 \mathrm{~K}$ and $101325 \mathrm{~Pa})$ to activity per cubic meter (using meteorological analysis data) for comparison with the model results. For the purpose of inverse modeling, the data were further decay-corrected to the time of the earthquake.
Two stations of the CTBTO network, Okinawa and Takasaki, are located in Japan, but ${ }^{133} \mathrm{Xe}$ measurements are made only at Takasaki. However, the Takasaki noble gas detections were, for an extended period of time, reaching the dynamic range of the system, meaning that measurements were so high that they became unreliable. In addition to that, there were also considerable memory effects. While some researchers (K. Ungar, personal communication, 2011) have made attempts to extract quantitative information from these 
Table 5. List of stations used for the ${ }^{137} \mathrm{Cs}$ inversions, sorted by longitude. Num gives the number of valid observations used for the inversion. NIES is the National Institute for Environmental Studies, JCAC is the Japan Chemical Analysis Center, JAEA is the Japan Atomic Energy Agency with data points from Furuta et al. (2011).

\begin{tabular}{|c|c|c|c|c|}
\hline Station name & Longitude & Latitude & Num & Data source \\
\hline Nankang & 121.6 & 23.5 & 23 & Hsu et al. (2012) \\
\hline Pengchiayu & 122.1 & 25.6 & 23 & Hsu et al. (2012) \\
\hline Okinawa & 127.9 & 26.5 & 39 & СТВТО \\
\hline Takasaki & 139.0 & 36.3 & 38 & СТВТО \\
\hline Wako & 139.6 & 35.8 & 31 & RIKEN \\
\hline Tsukuba & 140.1 & 36.0 & 24 & NIES \\
\hline Chiba & 140.1 & 35.7 & 37 & JCAC \\
\hline Tokai-mura & 140.6 & 36.4 & 69 & $\begin{array}{l}\text { JAEA S. Furuta, personal } \\
\text { communication (2011) }\end{array}$ \\
\hline Guam & 144.9 & 13.6 & 36 & СТВТО \\
\hline New Hanover & 150.8 & -2.6 & 36 & СТВТО \\
\hline Petropavlovsk & 158.8 & 53.0 & 40 & СТВТО \\
\hline Wake Island & 166.6 & 19.3 & 36 & СТВТО \\
\hline Midway Islan & -177.4 & 28.2 & 39 & СТВTO \\
\hline Sand Point & -160.5 & 55.3 & 37 & СТВТО \\
\hline Oahu & -158.0 & 21.5 & 39 & СТВТО \\
\hline Salchaket & -147.1 & 64.7 & 39 & СТВТО \\
\hline Vancouver & -123.2 & 49.2 & 39 & СТВTO \\
\hline Sacramento & -121.4 & 38.7 & 39 & СТВTO \\
\hline Yellowknife & -114.5 & 62.5 & 39 & СТВТО \\
\hline Ashland & -99.8 & 37.2 & 38 & СТВТО \\
\hline Resolute & -94.9 & 74.7 & 37 & СТВТО \\
\hline Melbourne & -80.6 & 28.2 & 39 & СТВТО \\
\hline Panama City & -79.5 & 9.0 & 39 & СТВТО \\
\hline Charlottesville & -78.4 & 38.0 & 39 & СТВТО \\
\hline Ottawa & -75.7 & 45.4 & 9 & $\begin{array}{l}\text { I. Hoffman, personal } \\
\text { communication (2011) }\end{array}$ \\
\hline St. John's & -52.7 & 47.6 & 39 & СТВТО \\
\hline Iceland & -21.9 & 64.1 & 13 & Ro5 \\
\hline Reykjavik & -21.8 & 64.1 & 38 & СТВTO \\
\hline Caceres & -6.3 & 39.5 & 16 & Ro5 \\
\hline Orsay & 2.2 & 48.7 & 19 & Ro5 \\
\hline Sola & 5.7 & 58.9 & 23 & Ro5 \\
\hline Schauinsland & 7.9 & 47.9 & 27 & СТВTO \\
\hline Braunschweig & 10.5 & 53.3 & 19 & Ro5 \\
\hline Osteras & 10.6 & 59.9 & 22 & Ro5 \\
\hline Spitsbergen & 15.4 & 78.2 & 31 & СТВТО \\
\hline Longyearbyen & 15.6 & 78.2 & 15 & Ro5 \\
\hline Stockholm & 17.6 & 59.2 & 39 & СТВТО \\
\hline Svanhovd & 30.0 & 69.4 & 20 & Ro5 \\
\hline Dubna & 37.3 & 56.7 & 39 & СТВTO \\
\hline Kuwait City & 47.9 & 29.3 & 39 & СТВТО \\
\hline Kirov & 49.4 & 58.6 & 36 & СТВТО \\
\hline Zalesovo & 84.8 & 53.9 & 39 & СТВTO \\
\hline Ulan-Bator & 106.3 & 47.9 & 39 & СТВТО \\
\hline Quezon City & 121.4 & 14.6 & 39 & СТВТО \\
\hline Ussuriysk & 132.0 & 44.2 & 38 & СТВТО \\
\hline Total & & & 1494 & \\
\hline
\end{tabular}


data, we decided to not use ${ }^{133} \mathrm{Xe}$ data from Takasaki for our inversions.

Regarding the ${ }^{137} \mathrm{Cs}$ measurements at Takasaki, there was another problem. During the first passage of the plume at this station, radioactivity entered the interior of the building. This resulted in a serious contamination, meaning that ${ }^{137} \mathrm{Cs}$ shows up continuously in the measurements since the initial event, even when it is probably completely absent in the ambient air. We applied a correction of the data (see http://www.cpdnp.jp/pdf/110818Takasaki_report_revise. pdf, downloaded on 16 August). Still, the contamination is a potential problem for the inversion, which may attempt to attribute the erroneously measured activity to direct releases from FD-NPP. Similar features can be noticed also in the data from the other Japanese stations. This might partly also be caused by contamination problems but we are lacking detailed information. In addition, resuspension either from the surroundings or from heavily contaminated areas elsewhere, is possible as well. In fact, such resuspension is necessary to explain the relatively more rapid decay of radiation dose rates in highly contaminated areas than in less contaminated areas (Yamauchi, 2012).

When using the CTBTO data, we found that these data alone could not provide sufficient constraints on the emissions (see also Sect. 4.1). This is true especially for ${ }^{137} \mathrm{Cs}$, for which the modeled concentrations far from Japan are highly sensitive to changes in the modeling of wet scavenging and thus the model uncertainties are large. We therefore added several non-CTBTO data sets. Measurements of ${ }^{137} \mathrm{Cs}$ at four Japanese stations were started only on 14-15 March when the accident at FD-NPP was already in full progress. For the first few weeks, the data collection followed irregular schedules, as attempts were made to take frequent measurements during plume passages. Some of the samples were collected over less than one hour, whereas some of the later samples were collected over several days.

We also added data from a few non-CTBTO stations outside Japan, two measuring ${ }^{133} \mathrm{Xe}$ and eleven measuring ${ }^{137} \mathrm{Cs}$ (see Tables 4 and 5). These stations were selected because they documented plume passages very well and offered good data quality. In particular, measurement data from a sub-set of the European network "Ring of five" (Ro5) were used. Measurements of this network following the FD-NPP accident were described by Masson et al. (2011). Measurements of ${ }^{137} \mathrm{Cs}$ from two stations in Taiwan were described by Hsu et al. (2012) and provided by these authors. ${ }^{133}$ Xe measurements made at Richland were described by Bowyer et al. (2011) and were kindly made available (H. Miley, personal communication, 2011). ${ }^{133} \mathrm{Xe}$ measurements made at Sidney (Canada) were kindly provided by K. Ungar and I. Hoffman (personal communication, 2011).

Measurements of ${ }^{137} \mathrm{Cs}$ deposition ("fallout") were performed by MEXT at 46 sites in all of Japan's 47 prefectures except Miyagi. The coordinates of these sites are confidential but were made available to us. Daily measurements using bulk samplers started on 18 March and a total of 1497 24-h samples were available for the period of our study. These data were quality-checked and updated for an earlier publication (Yasunari et al., 2011). Later revisions of a few data points by MEXT were taken into account. Furthermore, 12 deposition measurements were available from Tokai-mura with an irregular time resolution following rain events. Different deposition samplers were used at the various sites and, for the inverse modeling, it was assumed that the measured deposition is a result of both dry and wet deposition, even though dry deposition onto these samplers may not be representatitve for dry deposition onto the surrounding landscape.

The inversion needs information on the uncertainties associated with each observation value. For most data sets (all CTBTO data, plus some others), measurement uncertainties were available and used. Where such information was not available, we assumed a relative uncertainty of $5 \%$ for the concentration data and $10 \%$ for the deposition data and added absolute uncertainties of $0.2 \mathrm{mBq} \mathrm{m}^{-3}$ for ${ }^{133} \mathrm{Xe}$ concentration data, $1 \mu \mathrm{Bq} \mathrm{m}{ }^{-3}$ for ${ }^{137} \mathrm{Cs}$ concentration data, and $2 \mathrm{~Bq} \mathrm{~m}^{-2}$ for ${ }^{137} \mathrm{Cs}$ deposition data. Furthermore, to address the problem of ${ }^{137} \mathrm{Cs}$ contamination and resuspension at Japanese stations, we used 1 per mille of the highest previously measured ${ }^{137} \mathrm{Cs}$ concentration (or deposition) at a given station as the minimum observation uncertainty, unless the measured concentration (deposition) was below that threshold.

\subsection{Model simulations}

To simulate radionuclide dispersion, we used the Lagrangian particle dispersion model FLEXPART (Stohl et al., 1998; Stohl and Thomson, 1999; Stohl et al., 2005). This model was originally developed for calculating the dispersion of radioactive material from nuclear emergencies but has since been used for many other applications as well. Nuclear applications include, for instance, simulations of the transport of radioactive material from NPPs and other facilities (Andreev et al., 1998; Wotawa et al., 2010) or from nuclear bomb tests (Becker et al., 2010). FLEXPART is also the model operationally used at CTBTO for atmospheric backtracking and at the Austrian Central Institute for Meteorology and Geodynamics for emergency response as well as CTBT verification purposes.

For this study, FLEXPART was driven with three-hourly operational meteorological data from two different sources, namely the European Centre for Medium-Range Weather Forecasts (ECMWF) analyses, and the National Centers for Environmental Prediction (NCEP) Global Forecast System (GFS) analyses. The ECMWF data had 91 model levels and a resolution of $0.18^{\circ} \times 0.18^{\circ}$ in the region $126^{\circ}-180^{\circ} \mathrm{E}$ and $27^{\circ}-63^{\circ} \mathrm{N}$ and $1^{\circ} \times 1^{\circ}$ elsewhere, and the GFS data had 26 model levels and a resolution of $0.5^{\circ} \times 0.5^{\circ}$ globally. Both data sets do not resolve the complex topography of Japan very well, but in the simulations air masses from FD-NPP 
were blocked by the mountain chains from directly reaching western Honshu Island, where radionuclide measurement data indeed showed no direct impact of FD-NPP emissions.

To improve the a priori emissions by the inversion algorithm, it was necessary to run the dispersion model forward in time for each one of the 972 (3 layers $\times 324$ 3-h intervals between 12:00 UTC on 10 March and 00:00 UTC on 20 April) emission array elements. Each one of these 972 simulations quantified the sensitivity of downwind atmospheric activity concentrations and depositions to the emissions in a single time-height emission array element. The simulations extended from the time of emission to 20 April 00:00 UTC and carried one million particles each. A total of about 1 billion particles was used. Per simulation, unit masses of two tracers were released: firstly, a passive noble gas tracer and, secondly, an aerosol tracer that was subject to wet and dry deposition. Radioactive decay was not included in the model simulations, since all radionuclide observations and also the a priori emission data were corrected to the time of the earthquake for the purpose of the inverse modeling.

For the aerosol tracer, the simulations accounted for wet and dry deposition, assuming a particle density of $1900 \mathrm{~kg} \mathrm{~m}^{-3}$ and a logarithmic size distribution with an aerodynamic mean diameter of $0.4 \mu \mathrm{m}$ and a logarithmic standard deviation of 0.3. The wet deposition scheme considers below-cloud and within-cloud scavenging separately, assuming clouds are present where the relative humidity exceeds $80 \%$. Within-cloud scavenging coefficients are calculated as described in Hertel et al. (1995) and below-cloud scavenging coefficients are based on McMahon and Denison (1979), allowing also for sub-grid variability of precipitation rate. The wet deposition scheme is documented in the FLEXPART user manual available from http://transport.nilu.no/flexpart. Tests showed large sensitivity of simulated ${ }^{137} \mathrm{Cs}$ concentrations to the in-cloud scavenging coefficient. We explored this sensitivity by performing model simulations where all scavenging coefficients were scaled to 67 and $150 \%$ of their normal values. These sensitivity simulations, along with the reference simulation, were used as part of the ensemble for quantifying the model error needed by the inversion.

The agreement of model results (both using a priori and a posteriori emissions) with measurement data was better with GFS data than with ECMWF data. The fact that this was also found for ${ }^{133} \mathrm{Xe}$ which is not affected by wet scavenging, shows that GFS-FLEXPART captured the general transport better than ECMWF-FLEXPART. Furthermore, the wet scavenging of ${ }^{137} \mathrm{Cs}$ was much stronger with ECMWF data than with the GFS data, causing a strong underestimation of ${ }^{137} \mathrm{Cs}$ concentrations at sites in North America and Europe (see Sect. 4.4.1). Therefore, all results presented in this paper were produced using the GFS data as the reference data set. The ECMWF-based simulations are, however, used as ensemble members in the inversion to quantify the model uncertainties.

\subsection{Inversion algorithm}

In previous studies, we have developed an inversion algorithm to calculate the emissions of greenhouse gases (Stohl et al., 2009) or volcanic sulfur dioxide and ash emissions (Eckhardt et al., 2008; Kristiansen et al., 2010; Stohl et al., 2011a) based on original work by Seibert (2000). Depending on the application, the algorithm incorporates different types of observation data and can be based on forward or backward calculations with FLEXPART. A full description of the algorithm was given previously (Eckhardt et al., 2008; Stohl et al., 2009; Seibert et al., 2011) and, therefore, we provide only a short summary here. Our inversion setup is almost identical to that described by Stohl et al. (2011a), where volcanic ash emissions were derived as a function of time and altitude. The only further development is the use of ensemble model simulations to quantify the model uncertainty, described at the end of this section.

We want to determine radionuclide emissions as a function of time (324 3-hourly intervals between 10 March 12:00 UTC and 20 April 00:00 UTC) and altitude (three levels: $0-50 \mathrm{~m}, 50-300 \mathrm{~m}, 300-1000 \mathrm{~m}$ ), yielding a total of $n=972$ unknowns denoted as vector $\boldsymbol{x}$. For each one of the $n$ unknowns, a unit amount of radionuclide was emitted in FLEXPART and the model results (surface concentrations or deposition values) were matched (i.e., ensuring spatiotemporal co-location) with $m$ radionuclide observations (see Sect. 3.1) put into a vector $\boldsymbol{y}^{\boldsymbol{o}}$. Modeled values $\boldsymbol{y}$ corresponding to the observations can be calculated as

$y=M x$

where $\boldsymbol{M}$ is the $m \times n$ matrix of source-receptor relationships calculated with FLEXPART.

As the problem is ill-conditioned with the measurement data not giving a strong constraint on all elements of the source vector, regularization or, in other words, additional a priori information is necessary to obtain a meaningful solution. Including the a priori source vector $\boldsymbol{x}^{a}$, we can write

$\boldsymbol{M}\left(\boldsymbol{x}-\boldsymbol{x}^{a}\right) \approx \boldsymbol{y}^{o}-\boldsymbol{M x}^{a}$

and as an abbreviation

$M \tilde{\boldsymbol{x}} \approx \tilde{\boldsymbol{y}}$.

Considering only the diagonals of the error covariance matrices (i.e., only standard deviations of the errors while assuming them to be uncorrelated), the cost function to be minimized is

$$
\begin{aligned}
& J=(M \tilde{\boldsymbol{x}}-\tilde{\boldsymbol{y}})^{T} \operatorname{diag}\left(\sigma_{o}{ }^{-2}\right)(M \tilde{\boldsymbol{x}}-\tilde{\boldsymbol{y}})+\tilde{\boldsymbol{x}}^{T} \operatorname{diag}\left(\sigma_{x}{ }^{-2}\right) \tilde{\boldsymbol{x}} \\
& +(D \tilde{\boldsymbol{x}})^{T} \operatorname{diag}(\epsilon) D \tilde{\boldsymbol{x}} .
\end{aligned}
$$

The first term on the right hand side of Eq. (4) measures the misfit model-observation, the second term measures the deviation from the a priori values, and the third term measures the deviation from smoothness. $\sigma_{\boldsymbol{o}}$ is the vector of standard 
errors of the observations, and $\sigma_{x}$ the vector of standard errors of the a priori values. The operator $\operatorname{diag}(\boldsymbol{a})$ yields a diagonal matrix with the elements of $\boldsymbol{a}$ in the diagonal. $\boldsymbol{D}$ is a matrix with elements equal to -2 or 1 giving a discrete representation of the second derivative, and $\epsilon$ is a regularisation parameter determining the weight of this smoothness constraint compared to the other two terms.

The above formulation implies normally distributed, uncorrelated errors, a condition that we know to be not fulfilled. Observation errors (also model errors are subsumed in this term) may be correlated with neighboring values, and deviations from the prior sources are likely to be asymmetric, with overestimation being more likely than underestimation as zero is a natural bound. The justification for using this approach is the usual one: the problem becomes much easier to solve, detailed error statistics are unknown anyway, and experience shows that reasonable results can be obtained. Negative emission values can occur in this set-up but were removed in an iterative procedure by binding them more strongly to the positive a priori values.

Two important changes to the algorithm were made since our last application (Stohl et al., 2011a). The first change was required because the current problem is data-sparse and some individual emission values are not well constrained by the measurement data. This ill-conditioning was also encountered by Davoine and Bocquet (2007) in their inverse model study of the Chernobyl source term. For the volcanic ash problem, we used more than two million satellite observations (Stohl et al., 2011a), whereas here only of the order of one thousand observations were available. Partly this was compensated by reducing the number of vertical levels for which emissions were determined from 19 to 3 . Due to this poor vertical resolution, we removed the vertical smoothness condition used by Stohl et al. (2011a) and instead imposed a variable temporal smoothing condition. This was simply achieved by restructuring $\boldsymbol{D}$ and $\boldsymbol{\epsilon}$. The smoothing serves as an additional a priori constraint, which favors corrections of the a priori emissions that do not vary strongly with time. This stabilizes the inversion and reduces the noise level in the solution. Since there were a number of known incidents at FD-NPP when emission rates are suspected to have changed rapidly, we use a variable smoothness parameter $\boldsymbol{\epsilon}$. Weak smoothing was imposed when the a priori emissions changed rapidly, while stronger smoothing was imposed during periods with no reported events.

A second change was made to improve the representation of model error in the inversion. As described in Sect. 3.2, an ensemble of FLEXPART calculations was made using two meteorological data sets and changing the magnitude of the wet scavenging coefficients for ${ }^{137} \mathrm{Cs}$ to quantify the two most important sources of model error related to the meteorological input data and the wet scavenging parameters. The source-receptor relationships for all these model simulations were read into the inversion algorithm simultaneously to evaluate a range of a priori modeled concentration and de- position values. Their standard error was used as a proxy for the model error. Model and measurement error were combined into the observation error $\sigma_{o}=\sqrt{\sigma_{\text {meas }}^{2}+\sigma_{\text {mod }}^{2}}$, where $\sigma_{\text {meas }}$ is the measurement error and $\sigma_{\text {mod }}$ the model error.

While the inversion method formally propagates stochastic errors in the input data into an a posteriori emission uncertainty, the overall error is determined also by partly systematic other errors. For instance, the inversion assumes normally distributed errors, which is not the case. The inversion also treats all emission values and all observations as independent from each other, which is also not the case. However, lacking detailed error statistics, this cannot be formally accounted for. These additional errors can to some extent be explored with sensitivity experiments (see section 4.2.3).

For ${ }^{137} \mathrm{Cs}$, we have used measurements of both atmospheric activity concentrations as well as deposition to constrain the source term. It was already mentioned by Gudiksen et al. (1989) that it is preferable to use concentration measurements for inverse modeling because of the additional uncertainties related to modeling the deposition process, including the correct capture of location and time of precipitation events. However, in a data-sparse situation all available data should be used. There are 1497 Japanese deposition measurements available, while only 238 of the 1494 concentration measurements were made in Japan. By varying the wet scavenging parameters and the meteorological input data of our dispersion model, the uncertainties of the modeled deposition values are reasonably well quantified, so that the deposition data can provide valuable information. Furthermore, errors in modeling the deposition process will affect atmospheric concentrations and deposition values in the opposite way. Thus, combining these two types of data will partly lead to error compensation in the inverse modeling.

\section{Results}

\subsection{Sensitivity of the station network to emissions from FD-NPP}

Determining the emissions from FD-NPP is a data-poor problem and it is important to first explore to what extent the measurement data can actually provide constraints on the emissions. Figure 2 shows the total sensitivity of the measurement network to ${ }^{133} \mathrm{Xe}$ emissions, i.e., the emission sensitivities (source-receptor relationships) summed over all $m$ observation cases. This provides important information on the minimum source strength detectable by the station network. For the minimum detection threshold for a CTBTO station of $1 \mathrm{mBq} \mathrm{m}^{-3}$, an emission sensitivity of $1 \times 10^{-11} \mathrm{~Bq} \mathrm{~m}^{-3}$ per Bq s $\mathrm{s}^{-1}$ means that a 3-h-long emission pulse larger than $1 \times 10^{8} \mathrm{~Bq} \mathrm{~s}^{-1}$ is detectable. The largest expected emission rates are of the order of $10^{14} \mathrm{~Bq} \mathrm{~s}^{-1}$, six orders of magnitude larger. 


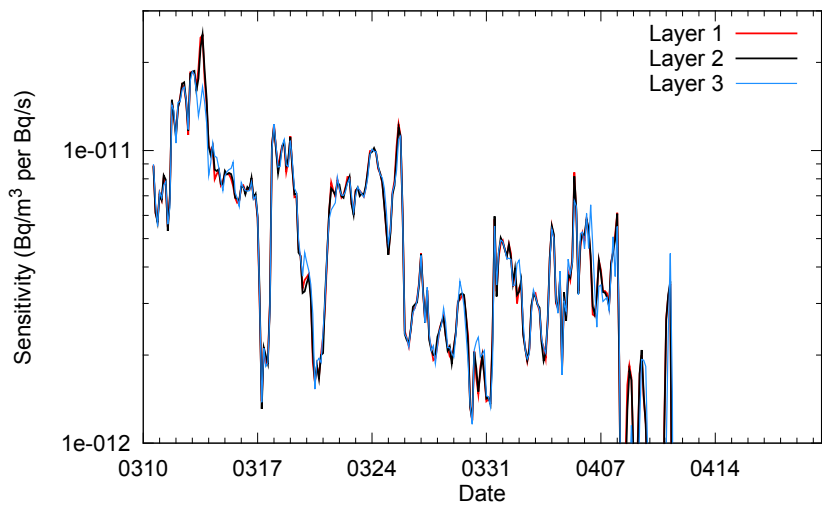

Fig. 2. Sensitivity of the station network to ${ }^{133} \mathrm{Xe}$ emissions at FDNPP. The sensitivities are calculated separately for emissions at the lowest layer (0-50 m, red), middle layer (50-300 m, black) and top layer (300-1000 m, blue).

The modeled emission sensitivity for March 2011 varies by about one order of magnitude and drops rapidly on 7 April 2011. The reason for the rapid decrease is that releases after 7 April had little chance to be sampled before 20 April by the ${ }^{133} \mathrm{Xe}$ measurement network consisting only of stations far from Japan (see Table 4). However, as we shall see later, this does not affect our capability to quantify the emissions from FD-NPP, since the entire inventory of ${ }^{133} \mathrm{Xe}$ was set free into the atmosphere before 16 March.

The accumulated emission sensitivities for the three emission layers are very similar most of the time (Fig. 2), suggesting similarity of transport. While differences can be larger when considering individual measurement samples separately, the overall similarity indicates that the inversion may not always be able to clearly distinguish the emissions from the three height layers.

To determine ${ }^{137} \mathrm{Cs}$ emissions, we used both air concentration as well as deposition data and we therefore consider the emission sensitivity for both data types separately (Fig. 3). In contrast to ${ }^{133} \mathrm{Xe}$, the emission sensitivity for ${ }^{137} \mathrm{Cs}$ varies by several orders of magnitude, both for the concentration and deposition data. Periods for which air from FD-NPP was sampled directly by the Japanese stations are characterized by high sensitivity, in contrast to periods when air from FD-NPP was transported to the Pacific Ocean and could be sampled only by remote stations. Removal of ${ }^{137} \mathrm{Cs}$ by precipitation scavenging adds more variability. Considering a minimum detectable ${ }^{137} \mathrm{Cs}$ concentration of $1 \mu \mathrm{Bq} \mathrm{m}{ }^{-3}$, an emission sensitivity of $1 \times 10^{-15} \mathrm{~Bq} \mathrm{~m}^{-3}$ per $\mathrm{Bqs}^{-1}$ (i.e., the lowest sensitivity before 12 April) allows detection of an emission of $1 \times 10^{9} \mathrm{~Bq} \mathrm{~s}^{-1}$, about two orders of magnitude less than the highest expected emission rates. For the deposition measurements, sensitivities vary between about $1 \times 10^{-12} \mathrm{~Bq} \mathrm{~m}^{-2}$ per Bq $\mathrm{B}^{-1}$ and $1 \times 10^{-6} \mathrm{~Bq} \mathrm{~m}^{-2}$ per $\mathrm{Bq} \mathrm{s}^{-1}$. With an optimistic detection threshold of $2 \mathrm{~Bq} \mathrm{~m}^{-2}$, emissions larger than $5 \times 10^{6} \mathrm{~Bq} \mathrm{~s}^{-1}$ to $5 \times 10^{12} \mathrm{~Bq} \mathrm{~s}^{-1}$ can be detected. This means that the deposition measurements alone constrain the source term only for certain periods when the FD-NPP plume passed directly over Japan.

Overall, we see that ${ }^{133} \mathrm{Xe}$ emissions of "expected" magnitude can be reliably detected by the observations throughout March, while this may not always be the case for ${ }^{137} \mathrm{Cs}$ emissions below "expected" peak values. Quantification of ${ }^{137} \mathrm{Cs}$ emissions is made even more difficult by the relatively large model errors (see section 4.3).

\subsection{Emissions}

Emission values reported in this section are corrected for radioactive decay to a reference time of 05:46 UTC on 11 March 2011, the time of the earthquake. Actual emissions are lower, especially for the short-lived ${ }^{133} \mathrm{Xe}$.

\subsubsection{Xenon-133}

Total a posteriori ${ }^{133} \mathrm{Xe}$ emissions obtained by the inversion are $15.3 \pm 3.1 \mathrm{EBq}$ (uncertainty range will be discussed later), $23 \%$ more than the a priori value of $12.4 \mathrm{EBq}$ (which is equal to the estimated inventory) and more than twice the estimated Chernobyl source term of 6.5 EBq (NEA, 2002). This value is in good agreement with independent results (Stohl et al., 2012) which we have obtained by using an atmospheric multi-box model $(16.7 \pm 1.9 \mathrm{EBq})$ as well as by comparing FLEXPART model calculations with CTBTO measurements of ${ }^{133} \mathrm{Xe}$ during the period 11 April to 25 May $2011(14.2 \pm 0.8 \mathrm{EBq}$ and 19.0 $\pm 3.4 \mathrm{EBq}$ when using GFS and ECMWF meteorological input data, respectively). All values obtained are higher than the calculated ${ }^{133} \mathrm{Xe}$ inventory, which confirms the full release of the noble gas inventory of FD-NPP. However, as emissions cannot exceed $100 \%$ of the inventory, there must have been an additional source of ${ }^{133} \mathrm{Xe}$, which presumably is the decay of iodine-133 $\left({ }^{133} \mathrm{I}\right.$, half-life $20.8 \mathrm{~h}$ ) into ${ }^{133} \mathrm{Xe}$ as this additional source. According to our ORIGEN calculations, the inventories of ${ }^{133} \mathrm{Xe}$ and ${ }^{133}$ I were almost identical at the time of the accident. Since the half-lives of mother and daughter nuclide have a ratio of approximately 1:6, the additional ${ }^{133} \mathrm{Xe}$ activity (decaycorrected to the time of the earthquake) generated by the decay of ${ }^{133} \mathrm{I}$ is about $16.5 \%$ of the original ${ }^{133} \mathrm{Xe}$ activity. Thus, the combined ${ }^{133} \mathrm{I}$ and ${ }^{133} \mathrm{Xe}$ inventories correspond to a total effective ${ }^{133} \mathrm{Xe}$ activity of $14.4 \mathrm{EBq}$, only 0.9 EBq less than the value for our a posteriori ${ }^{133} \mathrm{Xe}$ release but within its estimated uncertainty. Most of the ${ }^{133}$ I would have decayed to ${ }^{133} \mathrm{Xe}$ before the first venting at each unit was made and would have been released together with the originally present ${ }^{133}$ Xe. Smaller amounts of ${ }^{133}$ Xe produced later would still have been released as the damaged reactors would not have constituted a barrier to noble gas releases. Finally, small amounts of ${ }^{133} \mathrm{Xe}$ can be expected from the decay of ${ }^{133} \mathrm{I}$ that was released into the environment. 

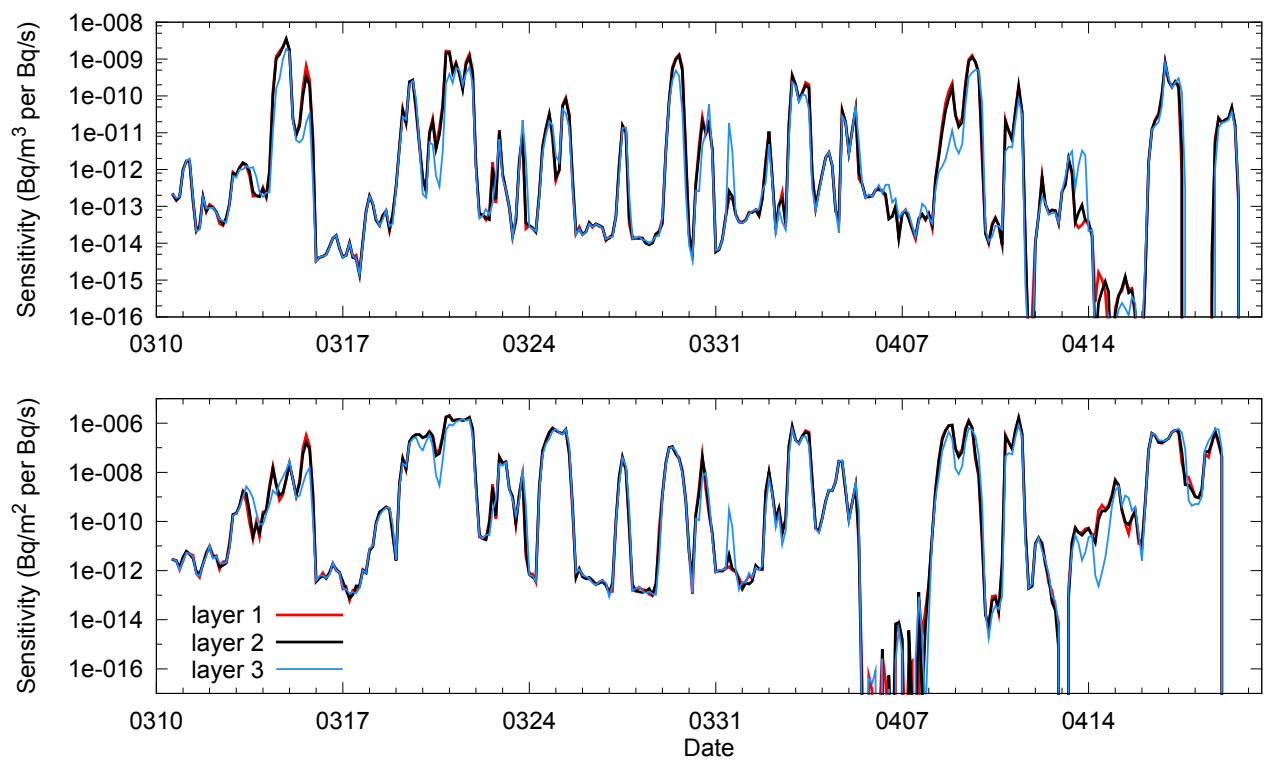

Fig. 3. Sensitivity of the station network to ${ }^{137} \mathrm{Cs}$ emissions at FD-NPP, for the atmospheric concentration measurements (upper panel) and for the deposition measurements (lower panel). The sensitivities are calculated separately for emissions at the lowest layer (0-50 m, red), middle layer (50-300 m, black) and top layer (300-1000 m, blue).
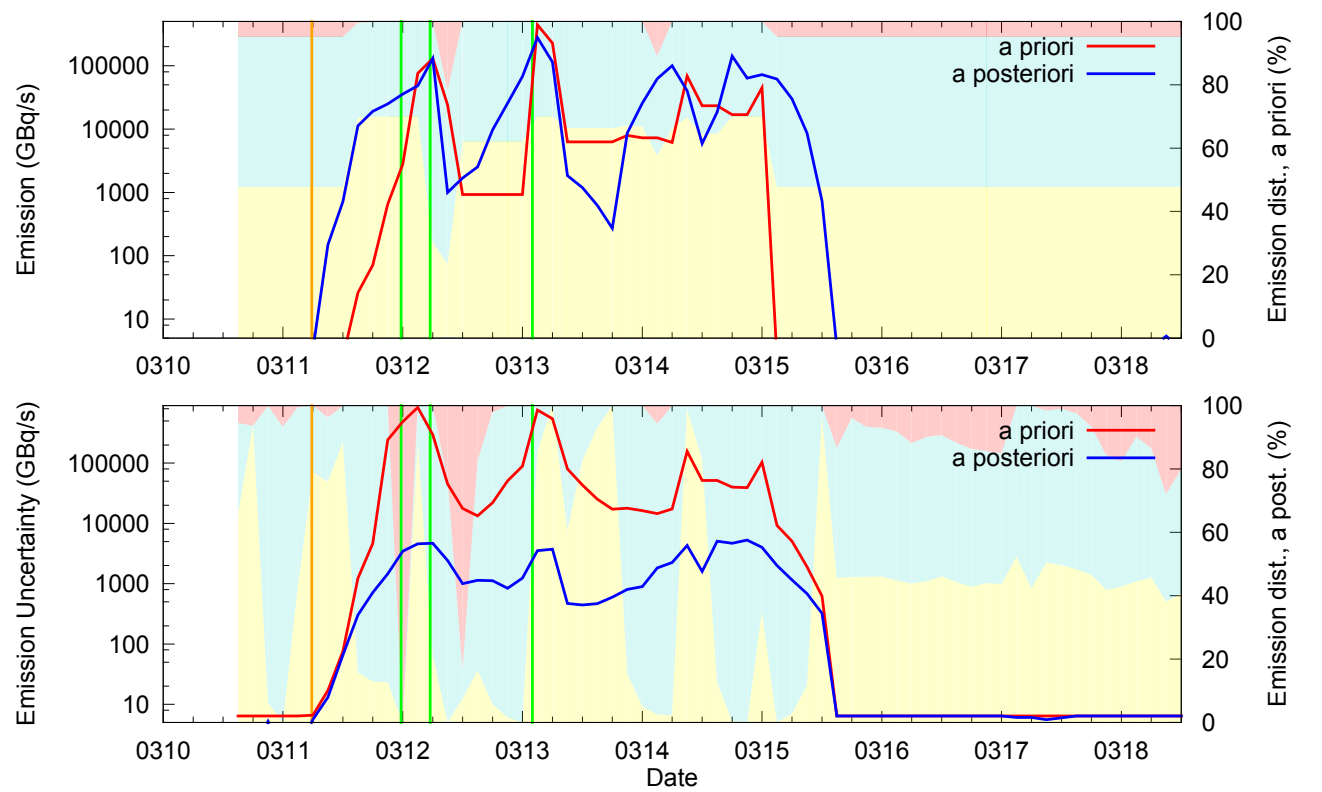

Fig. 4. Emissions of ${ }^{133} \mathrm{Xe}$ used a priori (red line) and obtained a posteriori by the inversion (blue line) (upper panel), as well as associated uncertainties (lower panel). The vertical distribution of the emissions over the three layers, with scale on the right hand side, is shown by the background colors (0-50 m, light yellow; 50-300 m; light turquoise, 300-1000 m, light red) for the a priori emissions (upper panel) and the a posteriori emissions (lower panel). The orange vertical line indicates the time of the earthquake, and the green vertical lines mark the times when the first venting operations are reported. The data shown in this plot are available as Supplement.

The time variation of a priori and a posteriori emissions is generally quite consistent (Fig. 4), both suggesting that the entire ${ }^{133} \mathrm{Xe}$ inventory was released between 11 and 15 March 2011. However, the a posteriori emissions start $6 \mathrm{~h}$ earlier and end $12 \mathrm{~h}$ later than our first guess estimate. This is a robust feature of the inversion, which was obtained also with reduced smoothness, increased a priori uncertainty and for both meteorological data sets. While errors in the timing of emissions are possible with our inversion method, they should be smaller than the $18 \mathrm{~h}$ between the time of the 

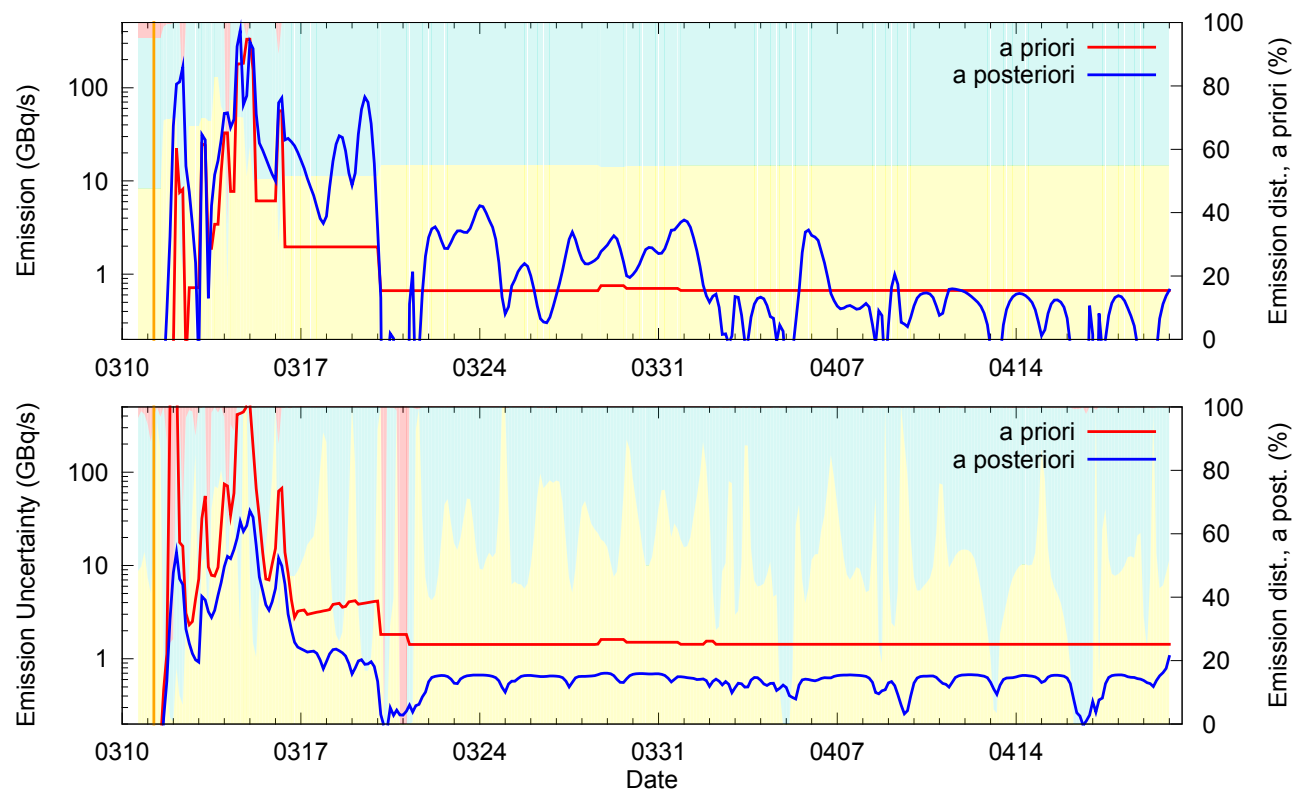

Fig. 5. Emissions of ${ }^{137} \mathrm{Cs}$ used a priori (red line) and obtained a posteriori by the inversion (blue line) (upper panel), as well as associated uncertainties (lower panel). The vertical distribution of the emissions over the three layers, with scale on the right hand side, is shown by the background colors (0-50 m, light yellow; 50-300 m; light turquoise, 300-1000 m, light red) for the a priori emissions (upper panel) and the a posteriori emissions (lower panel). The orange vertical line indicates the time of the earthquake. The data shown in this plot are available as Supplement.

earthquake (and also the start of our a posteriori emissions) and the reported time of the first successful venting. The early start of a posteriori emissions could be due to a noble gas release as a consequence of the emergency shutdown of the reactors, possibly enhanced by structural damage from the earthquake and/or leaks due to overpressure. Also the injection of cold water through the emergency core cooling systems and associated thermal stress on fuel claddings may contribute to this release. Finally, workers temporarily opened an air lock in the reactor building and closed it only after they observed a white "cloud" coming out. Thus, some radioactivity seems to have leaked out already before the pressure relieve valves were opened in reactor unit 1 at 00:15 on 12 March, according to the Report. Notice, however, that the retrieved emissions during the first six hours after the earthquake are not very large. Large emissions are retrieved from 12:00 UTC on 11 March, the suspected time of failure of the primary containment vessel, according to the Report. For a detailed discussion of this early start of the emissions, we refer to Stohl et al. (2011b).

The emission peaks on 12, 13, and 14 March are associated with venting events at units 1,3 and 2 , respectively. It is interesting to notice that in all three cases our a posteriori emissions start increasing earlier than our first guess emissions and drop more strongly at the end of the venting. This seems to indicate that contaminated air was leaking from the containment as pressure was building up, even before active venting started.
In our first guess, ${ }^{133} \mathrm{Xe}$ emissions end after a final peak presumably caused by a hydrogen explosion which damaged the wet well of unit 2 at 21:00 UTC on 14 March. Our a posteriori emissions, however, continue until 12:00 UTC on 15 March. The pressure vessel and dry well of unit 2 were reported to be at ambient pressure only at 21:00 UTC on 15 March, and various valve operations are reported for unit 3 until 20 March. This could explain ongoing emissions at least until 15 March, especially if we consider that the core degradation may still have been in progress. The inversion results show no emissions after 15:00 UTC on 15 March. Partly, this may be related to the decreasing emission sensitivity at that time (see Fig. 2), which also leads to rather small reductions in the emission uncertainty after 15 March (lower panel of Fig. 4). Therefore, we cannot rule out the possibility that minor emissions have persisted even after 15 March, but they would only constitute a small fraction of the total emission.

Regarding the vertical emission distribution, the inversion attributes a larger fraction to layer $2(50-300 \mathrm{~m})$ than the first guess, probably indicating that thermal plume rise was often important (Fig. 4, lower panel). However, the vertical attribution is very noisy and emissions fluctuate between layers 1 and 2. A clear separation of the two layers is not possible at a $3 \mathrm{~h}$ time resolution. The inversion does not increase emissions from layer $3(300-1000 \mathrm{~m})$, with two notable exceptions on 12 March when emissions were high. They occurred around the times of the unit 1 venting and hydrogen explosion at 06:36 UTC. 
The emission uncertainty as calculated by the inversion scheme is reduced by up to three orders of magnitude (lower panel of Fig. 4). This is achieved also because of the smoothness criterion, which provides a constraint on the a posteriori emissions and formally reduces uncertainty. However, it is dubious that it really leads to a reduction of uncertainty. Thus, the emission uncertainty plot mainly serves the purpose of identifying periods when the observations provide a strong (large uncertainty reduction) or weak constraint (small error reduction). Real uncertainties will always be larger than the calculated a posteriori uncertainties and will be explored in Sect. 4.2.3.

\subsubsection{Caesium-137}

The upper panel of Fig. 5 shows the a priori and a posteriori emissions of ${ }^{137} \mathrm{Cs}$. The total a posteriori ${ }^{137} \mathrm{Cs}$ emission is $36.6 \mathrm{PBq}, 70 \%$ more than the first guess (Table 3 ) and about $43 \%$ of the estimated Chernobyl emission of $85 \mathrm{PBq}$ (NEA, 2002). Our total a posteriori emission is lower than the first estimate of $66 \mathrm{PBq}$ published by the Central Institute for Meteorology and Geodynamics (2011) on 22 March, but considerably higher than the estimate of Chino et al. (2011) of $13 \mathrm{PBq}$. Both previous estimates were based on only few selected measurements. Our emission is in relatively good agreement with the Institut de Radioprotection et de Surete Nucleaire (2011) estimate of $30 \mathrm{PBq}$ caesium (including Cs isotopes other than ${ }^{137} \mathrm{Cs}$ ) for the period $12-22 \mathrm{March}$. It is compatible with the range of inverse modeling estimates given by Winiarek et al. (2012) and their lower bound of $12 \mathrm{PBq}$.

The first emission peak on 12 March, which in our first guess is related to the hydrogen explosion in reactor unit 1 was corrected upward substantially by the inversion. We notice in particular that the inversion strongly increases the fraction of the ${ }^{137} \mathrm{Cs}$ emissions into the third layer (300$1000 \mathrm{~m}$ ) at that time (lower panel of Fig. 5), which was seen already for ${ }^{133} \mathrm{Xe}$. This suggests an elevated injection of radioactivity into the atmosphere due to the explosion. The emission peaks on 13 March and just past 00:00 UTC on 14 March are not changed much by the inversion, however an earlier onset is suggested for the second peak as was the case for ${ }^{133} \mathrm{Xe}$. The inversion also suggests a large fraction of these emissions to be injected in the $300-1000 \mathrm{~m}$ layer.

The highest emission rates of about $400 \mathrm{GBq} \mathrm{s}^{-1}$ occurred on 14 March after 12:00 UTC until 15 March at 03:00 UTC and are related to a hydrogen explosion in unit 4 and a suspected hydrogen explosion in unit 2 , which occurred nearly at the same time (around 21:00 UTC on 14 March). Chino et al. (2011) estimate a release rate of about $280 \mathrm{GBq} \mathrm{s}^{-1}$ from 00:00-06:00 UTC on 15 March, quite comparable to our own value for the same period, but their maximum persists only for six hours, whereas we find two separate maxima within a 15-h period.
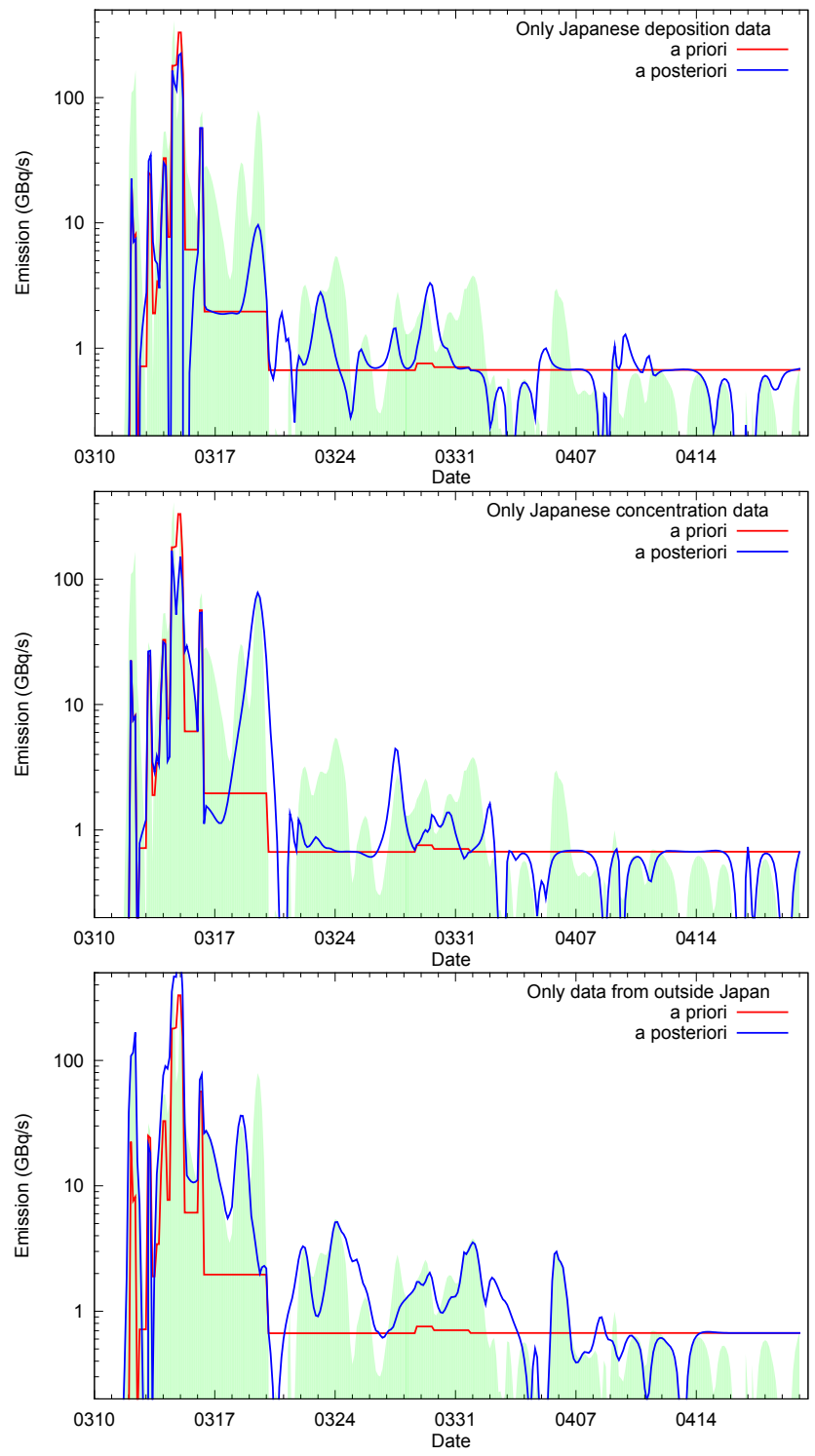

Fig. 6. Sensitivity of ${ }^{137} \mathrm{Cs}$ a posteriori emissions to changes in the input measurement data: Results obtained when using only Japanese deposition data (top panel), when using only Japanese concentration data (middle panel), and when using only nonJapanese concentration data (bottom panel). Shown are a priori emissions (red line), a posteriori emissions (blue line) and a posteriori emissions based on the full data set (repeated from Fig. 5, green shading in background).

For the period from 16-19 March, the inversion increases the a priori emissions by more than an order of magnitude. Especially on 19 March, the emissions are comparable to the peaks on 12-15 March. Our method does not allow us attributing the emissions directly to a particular reactor unit. However, spraying of water on the spent-fuel pool in unit 4 started on 19 March at 23:21 UTC and at that time our a posteriori emissions decrease by orders of magnitude. This 
Table 6. Sensitivity of a posteriori total emissions to scaling the a priori emissions by factors ranging from $20 \%$ to $500 \%$, and to replacing the GFS meteorological data with ECMWF data. For the ${ }^{137}$ Cs inversions, total emissions are also reported when using only deposition data, only Japanese concentration data, and only non-Japanese data. All values are reported relative to the reference emission.

\begin{tabular}{lrrrrrrrr}
\hline A priori & $20 \%$ & $50 \%$ & $200 \%$ & $500 \%$ & ECMWF & only depo & only Japan & only non-Japan \\
\hline${ }^{133} \mathrm{Xe}$, a posteriori & $92 \%$ & $95 \%$ & $107 \%$ & $125 \%$ & $104 \%$ & - & - & - \\
${ }^{137} \mathrm{Cs}$, a posteriori & $63 \%$ & $85 \%$ & $119 \%$ & $179 \%$ & $68 \%$ & $55 \%$ & $59 \%$ & $150 \%$ \\
\hline
\end{tabular}

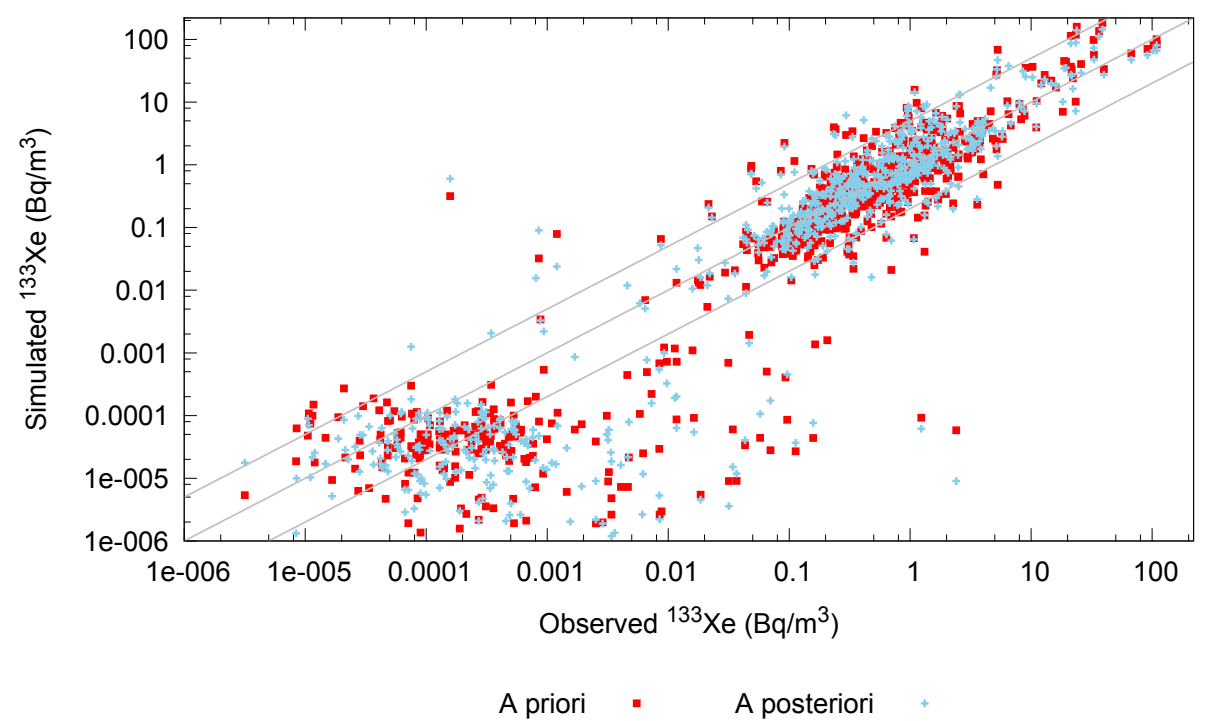

Fig. 7. Scatter plot of observed and simulated ${ }^{133}$ Xe concentrations, based on a priori (red squares) and a posteriori (blue crosses) emissions. The gray line in the middle is the 1:1 line and upper and lower lines represent factor of 5 over- and underestimates.

coincidence suggests that these emissions are related to the spent-fuel pond in unit 4. Such emissions from spent fuel have also been suggested on the basis of radionuclide concentration ratios (Kirchner et al., 2012). Notice that the a posteriori emissions are higher than the first guess emissions before the start of the water spraying, but lower afterwards, so this decrease is not primarily related to the much smaller drop in first guess emissions. Sensitivity calculations with unit 4 emissions removed from the a priori still showed the drop in emissions. Notice also that the period is well constrained by measurement data, as shown by the large uncertainty reduction (lower panel of Fig. 5).

For the period between 21 March and 10 April, the inversion yields variable emissions, with total emissions higher than in our first guess. The emission fluxes are one to two orders of magnitude smaller than fluxes until 19 March and the timing of these emissions is not captured particularly well by the inversion, as sensitivity tests show time shifts of the emission peaks. However, all sensitivity experiments do show such peaks and total emissions higher than the first guess.

\subsubsection{Some sensitivity tests}

We performed many sensitivity tests, and Table 6 reports how total emissions changed in some of these tests. When scaling the a priori emissions by values between $20 \%$ and $500 \%$, the a posteriori ${ }^{133} \mathrm{Xe}$ emissions change only between 92 and $125 \%$ of their reference value, whereas the ${ }^{137} \mathrm{Cs}$ emissions vary between 63 and $179 \%$. Thus, the ${ }^{133} \mathrm{Xe}$ emissions are almost independent of the chosen a priori emissions, while the ${ }^{137} \mathrm{Cs}$ emissions are much less robust. For these tests, we have changed the a priori emissions aggressively. For a factor 2 change of the a priori emissions, the a posteriori ${ }^{137} \mathrm{Cs}$ emissions change only between 85 and $119 \%$. Replacing the GFS data with ECMWF data for driving the reference model simulation increases the total emissions by $4 \%$ for ${ }^{133} \mathrm{Xe}$ and decreases them by $32 \%$ for ${ }^{137} \mathrm{Cs}$. In all these tests, the temporal variation of the emissions remains very similar.

Another interesting test is to split the ${ }^{137} \mathrm{Cs}$ measurement data set into Japanese deposition data, Japanese air concentration data, and non-Japanese air concentration data. Inversions performed separately for these data sets show a relatively large degree of consistency (Fig. 6). The weakest constraint is provided by Japanese deposition data (Fig. 6, top 

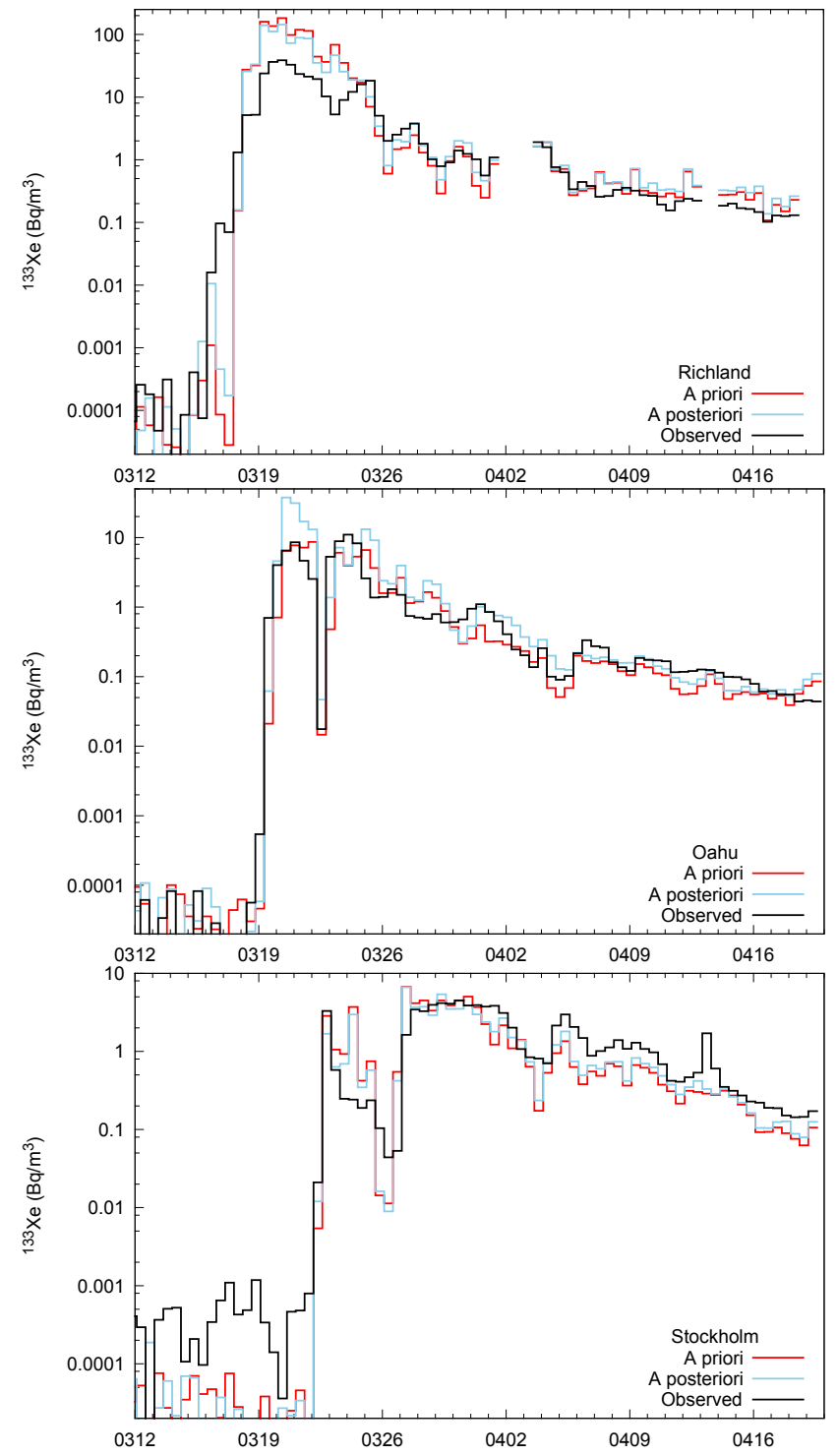

Fig. 8. Time series of observed (black line) and simulated ${ }^{133} \mathrm{Xe}$ concentrations, based on a priori (red line) and a posteriori (blue line) emissions, for the stations Richland (top panel), Oahu (middle panel) and Stockholm (bottom panel).

panel) because of the sensitivity "gaps" (see section 4.1) and large uncertainties in the modeled deposition. This is particularly true for emissions until 18 March because all deposition measurements (except for one sample taken at Tokai-mura) started later. Therefore, the inversion result is bound strongly towards the first guess most of the time. However, in consistency with the reference inversion, the deposition data require higher than expected emissions on 19 March, a steep drop in emissions on 20 March and several emission maxima after 21 March. The total emission is $45 \%$ smaller than in our reference inversion (Table 6), partly because the solution is bound strongly towards the lower first guess emissions.
The Japanese concentration data also provide a relatively weak constraint at the beginning (Fig. 6, middle panel), because of constant westerly winds, and the only available station before 15 March, Takasaki, failed for one day after the plume was first striking on 14 March, caused by the detector contamination problem. From 15 March the constraint is strong for some important periods (e.g., 15-16 March, 18 20 March) when the FD-NPP plume was subsequently transported over Japan. During these periods, the Japanese concentration data also drive the shape of the reference inversion results. However, the derived total emission when using only the Japanese concentration data is $41 \%$ smaller (Table 6).

The inversion using data only from outside Japan yields the highest overall emissions (Fig. 6, bottom panel), 50\% above the reference value (Table 6). The magnitude of the emissions is sensitive to changes of the wet scavenging parameters. Enhanced scavenging may be compensated for in the inversion by higher emissions to improve agreement between model results and observations (although the effect of this is reduced by the higher model uncertainty for cases with strong scavenging, which gives them a lower weight in the inversion). The global data provides a continuous constraint on the emissions, without major sensitivity gaps. It is therefore encouraging that the inversion using the global data reproduces many of the deviations from the first guess seen when using the Japanese data sets. This yields confidence also for those periods not well sampled by the Japanese stations. However, the magnitude of the highest emission peak on 15 March is obviously quite uncertain, as the first guess is corrected upward with the global data, but downward using the Japanese data, and this change also explains the substantial difference in total emissions (Table 6). This has implications for the total deposition over Japan, since in our model simulations it is these emissions which led to the largest ${ }^{137} \mathrm{Cs}$ deposition in Japan.

The sensitivity tests reported here as well as other tests show that important features such as large emission peaks are relatively robust against changes of the inversion setup. Based on the sensitivity tests, we estimate that the total ${ }^{133} \mathrm{Xe}\left({ }^{137} \mathrm{Cs}\right)$ a posteriori emissions are accurate within $20 \%$ $(45 \%)$. Individual 3-hourly emission fluxes are more uncertain.

\subsection{Comparison between modeled and measured concentrations and depositions}

\subsubsection{Xenon-133}

Figure 7 shows a scatter plot of all available ${ }^{133} \mathrm{Xe}$ observations versus simulation results using the a priori and the a posteriori emissions. There exists a highly variable background of ${ }^{133} \mathrm{Xe}$ in the atmosphere due to emissions from nuclear facilities (Wotawa et al., 2010). Our model does not simulate that background and we have therefore added a random, normally distributed value with a standard deviation 


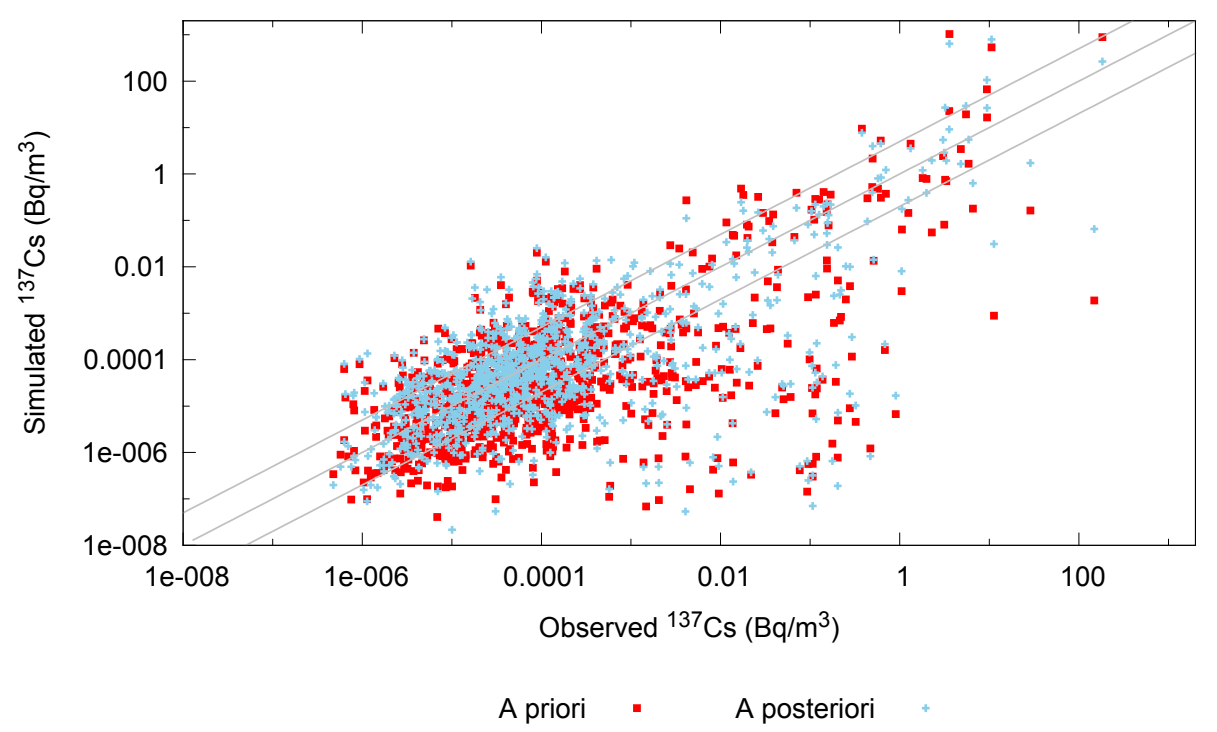

Fig. 9. Scatter plot of observed and simulated ${ }^{137}$ Cs concentrations, based on a priori (red squares) and a posteriori (blue crosses) emissions. The gray line in the middle is the 1:1 line and upper and lower lines represent factor of 5 over- and underestimates.

of $1 \times 10^{-4} \mathrm{~Bq} \mathrm{~m}^{-3}$ to every simulated concentration. This was done also to allow plotting of otherwise zero concentration values on the logarithmic plot. Consequently, one cannot expect any correlation between measured and simulated values in the lower left part of Fig. 7, which is dominated by background variability outside the FD-NPP plume. Some of the observed values, for which the corresponding simulated values are below $2 \times 10^{-4} \mathrm{~Bq} \mathrm{~m}^{-3}$, are clearly elevated. As background values at some stations can reach several $\mathrm{mBq} \mathrm{m}{ }^{-3}$, many of these data points probably indicate an enhanced background rather than that the model did not capture the FD-NPP plume.

Data points in the upper right part of the figure all reflect the emissions from FD-NPP and for these data points, the modeled and observed values show a tight correlation. Most of the simulated values fall within a factor of five of the observed values. While the model results using our first guess emissions are already well correlated with the measurements, the inversion clearly improves the correspondence, with most of the data points falling closer to the 1:1 line.

Comparisons between simulated and observed time series of ${ }^{133} \mathrm{Xe}$ are shown at the example of Richland, Oahu and Stockholm (Fig. 8). The locations of these sites are shown in Fig. 13 (see also Table 4). At Richland (Fig. 8, top panel), the plume first arrived on 16 March. The arrival time is well simulated but the modeled values drop back to nearly background on 17 March before rising again, whereas the measured concentrations increase continuously. At the station Sidney (not shown), which is relatively close to Richland, the measurements in fact show a similar behavior as our model results for Richland. At Richland, the model overestimates the measured peak concentrations on 19-20 March by a factor of about three, whereas at Sidney it underpredicted. Since the two stations sampled the same part of the radioactive cloud, the inversion could not bring the model results in agreement with the measurements at both stations. Overall, however, the model captures the ${ }^{133} \mathrm{Xe}$ variability at both sites quite well. The time series also shows the formation of a hemispheric cloud of ${ }^{133} \mathrm{Xe}$. After arrival of the FD-NPP plume at Richland, there is considerable concentration variability which decreases rapidly as ${ }^{133} \mathrm{Xe}$ becomes uniformly distributed throughout the Northern Hemisphere. The steady concentration decrease in April is mainly due to radioactive decay but also some further mixing into the tropical and polar atmospheres.

At Oahu (Fig. 8, middle panel), which is closer to Japan than Richland, the first detection of the FD-NPP plume was made later than at Richland, on 19 March. This happened because this part of the radioactive cloud was first transported to the eastern North Pacific in the midlatitudes, before curving to the south and then to the west. Again, the timing of the plume arrival is well captured, although the model initially underestimates the measured concentrations but then overpredicts the first measured peak. The model successfully captures a 1-day concentration minimum on 22 March and also some subsequent concentration variability.

At Stockholm (Fig. 8, bottom panel), the plume arrived on 22 March and this was also very well captured by the model. Simulated concentrations are within a factor of two to the observations and the inversion brings the simulated values closer to the observations most of the time. Before the arrival of the FD-NPP plume, the model simulations underestimate the observations, a consequence of a too low background added to the model results. 


\subsubsection{Caesium-137}

Figure 9 compares measured and simulated ${ }^{137} \mathrm{Cs}$ concentrations. Again, a random, normally distributed background concentration was added to every simulated concentration value. Typical background values in Europe are of the order of $0.5 \mu \mathrm{Bq} \mathrm{m}^{-3}$ (Vallés et al., 2009), which was used for the standard deviation of the random values. The agreement between the model and the observations is worse than for ${ }^{133} \mathrm{Xe}$, a consequence of the added complexity of modeling wet and dry removal of the particles carrying ${ }^{137} \mathrm{Cs}$. However, there is still a clear correlation between modeled and observed concentrations and the inversion further improves the agreement, especially for the highest concentration values.

Figure 10 shows time series of measured and modeled ${ }^{137}$ Cs concentrations at Tokai-mura, Oahu and Stockholm (station locations are shown in Fig. 14, see also Table 5). At Tokai-mura (Fig. 10, top panel), the plume arrivals on 14, 21 and 30 March as well as several peaks in April are well captured by the model, although the differences between measured and modeled concentrations are often substantial. The simulated concentrations drop to background levels in between plume passages, whereas measured concentrations remain strongly elevated, especially in March after the most heavy contamination events. Possible causes are the resuspension of ${ }^{137} \mathrm{Cs}$ from contaminated surfaces (see also Yamauchi, 2012), which is not treated in our model, and detector contamination similar to Takasaki. This behavior is also seen at the other Japanese stations.

At Oahu (Fig. 10, middle panel), the main plume events are again captured, but the agreement between model and measurements is much worse than for ${ }^{133} \mathrm{Xe}$. As for ${ }^{133} \mathrm{Xe}$, the model overpredicts the main concentration peaks for this site.

At Stockholm (Fig. 10, bottom panel), the model generally overpredicts in March and underpredicts in April. The low measured concentrations between 22 and 27 March are surprising, given that the ${ }^{133} \mathrm{Xe}$ concentrations during that time period are almost as high as at the end of March. There must have been very strong wet scavenging of ${ }^{137} \mathrm{Cs}$ to explain the low ${ }^{137} \mathrm{Cs} /{ }^{133} \mathrm{Xe}$ ratios. Indeed, the model simulations show that this part of the plume was lifted to the free troposphere just downwind of Japan and then descended back to the surface over the North Atlantic. The model must have underestimated the wet scavenging in this case. However, this is not typical as otherwise the inversion would have reduced the emissions to improve the agreement between the model and the measurements.

Figure 11 shows a scatter plot of simulated versus observed ${ }^{137} \mathrm{Cs}$ deposition values. As for the concentration data, the data set is dominated by zero values and in this case there are also many zero observations. To show these data on the logarithmic plot, we added a normally distributed random value with a standard deviation of $1 \mathrm{~Bq} \mathrm{~m}^{-2}$ (day) ${ }^{-1}$

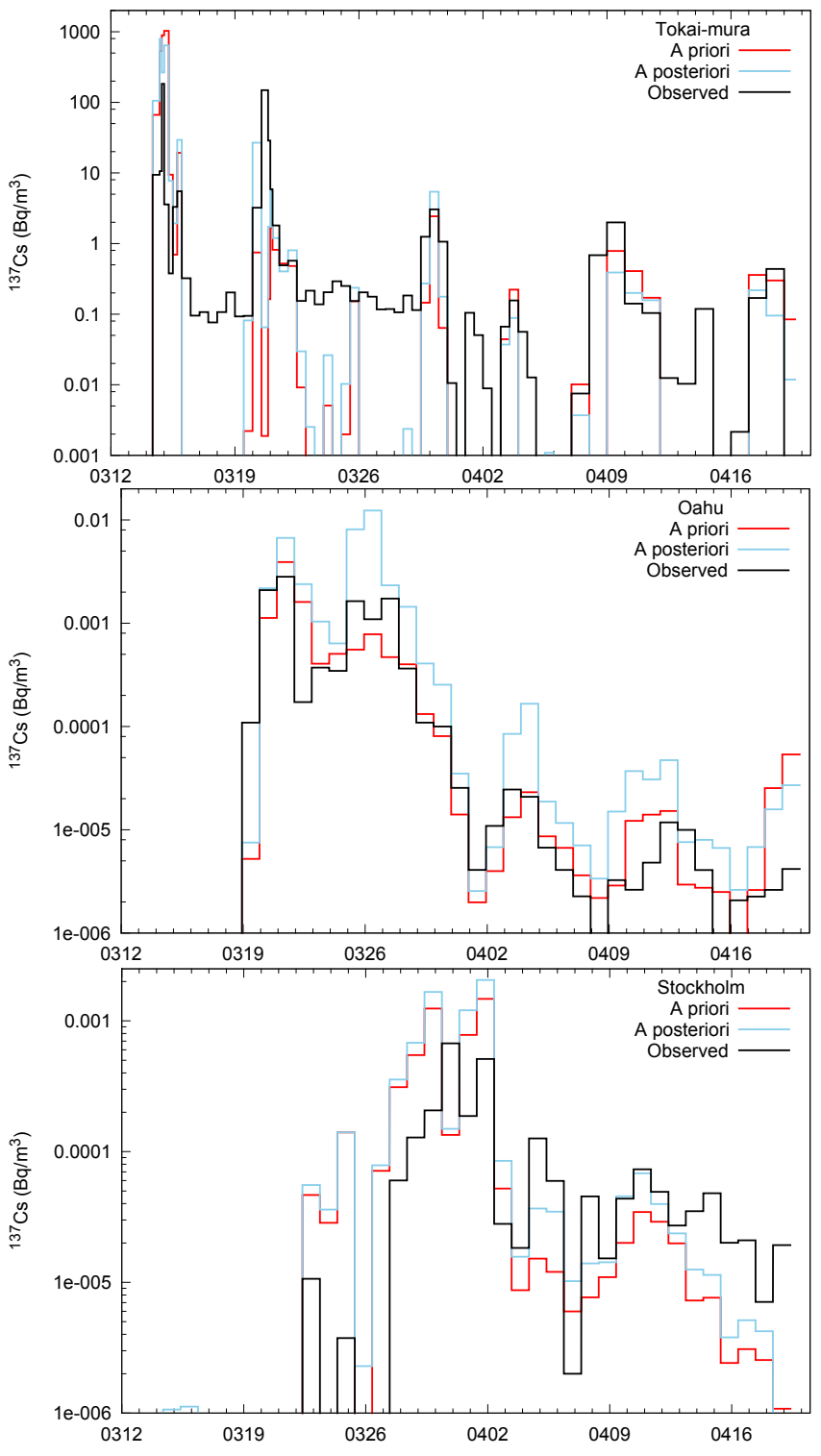

Fig. 10. Time series of observed (black line) and simulated ${ }^{137} \mathrm{Cs}$ concentrations, based on a priori (red line) and a posteriori (blue line) emissions, for the stations Tokai-mura (top panel), Oahu (middle panel) and Stockholm (bottom panel).

to every zero observation and a random value with a standard deviation of $2 \mathrm{~Bq} \mathrm{~m}^{-2}$ (day) ${ }^{-1}$ to every simulated deposition. Therefore, no correlation is expected for the data in the lower left part of the figure. There is not a particularly tight correlation between the observations and the model simulations near the high end of the data range. However, the model has little overall bias and the inversion clearly reduces the scatter. There are many cases for which the model suggests background values but observations are enhanced. Again, we suspect this to be due to resuspension of previously deposited ${ }^{137} \mathrm{Cs}$ or to contamination problems. However, some 


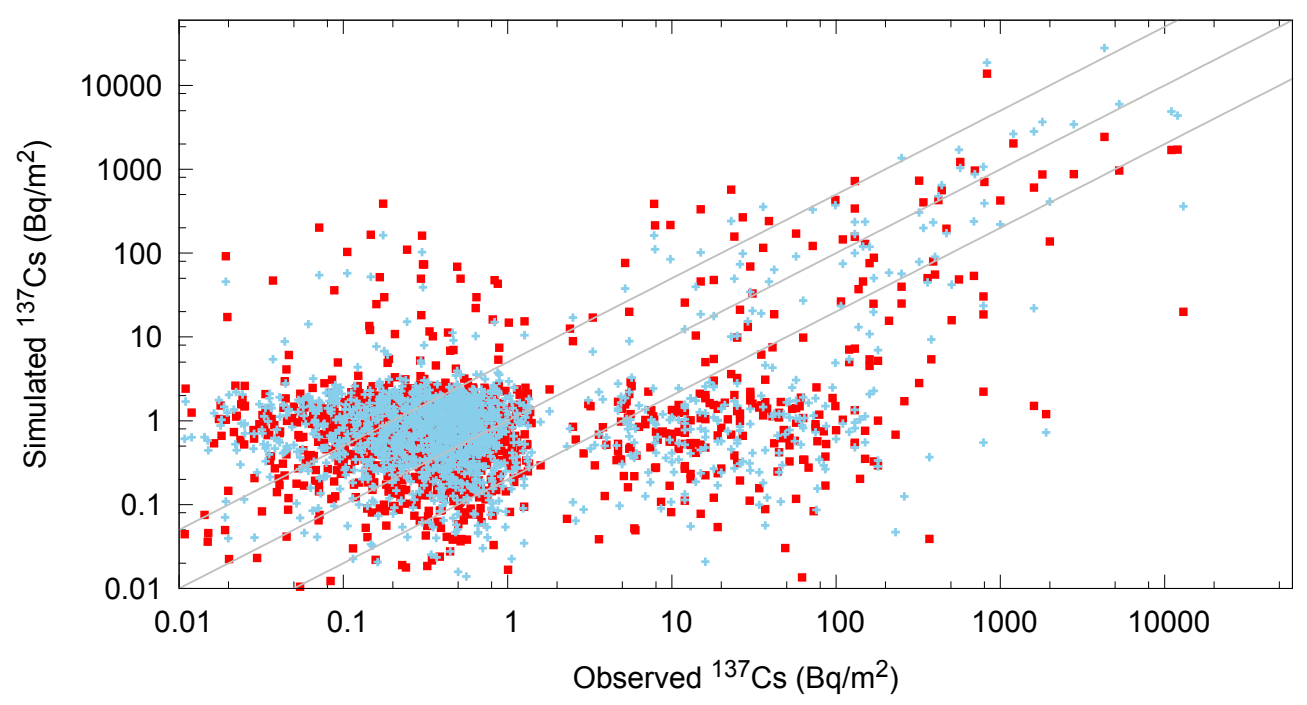

A priori - A posteriori

Fig. 11. Scatter plot of observed and simulated ${ }^{137} \mathrm{Cs}$ deposition values, based on a priori (red squares) and a posteriori (blue crosses) emissions. The gray line in the middle is the 1:1 line and upper and lower lines represent factor of 5 over- and underestimates.

cases may be related to precipitation events not captured by the model, and there are also cases where the model gives deposition values of about $100 \mathrm{~Bq} \mathrm{~m}^{-2}$, which overestimate the observations, related to precipitation events that were simulated but did not occur in reality. Notice that almost all deposition observations were made after $18 \mathrm{March}$, which is after the most severe modeled deposition event (see Sect. 4.4).

Figure 12 shows a comparison of measured and modeled deposition for Tokyo. No measurement data are available for the first plume passage over Tokyo on 14-15 March, but the deposition during 20-22 March is well simulated. After that, the model underestimates the measurements almost continuously, except for a relatively well captured event on 11 April. Again, we suspect contamination or resuspension caused the continuously high measured values that persisted even when no rain occurred.

\subsection{Dispersion of radionuclides from FD-NPP}

The purpose of this section is to describe the dispersion and deposition of radionuclides from FD-NPP during certain phases of the accident both over Japan and on a hemispheric scale. Morino et al. (2011) have already presented a short description of the main transport events in the vicinity of Japan in March, but their analysis was not based on a source term constrained by an extensive measurement data set. Here, transport is described by FLEXPART simulations based on the GFS meteorological analyses, but reference is also made to simulations using the ECMWF data. The complex topography of Japan is not well represented in these data and so FLEXPART simulations do not resolve fine-scale flow and precipitation features. Thus, the regional-scale results must be interpreted with caution.

For the interpretation of the meteorological situation over Japan, we used daily surface pressure and frontal analyses from the Japanese Meteorological Agency (http://www. data.jma.go.jp/fcd/yoho/data/hibiten/2011/1103.pdf, downloaded on 19 September 2011) in addition to the GFS and ECMWF analysis data. Hourly precipitation radar data for Honshu Island were viewed at this website: http://agora.ex.nii.ac.jp/earthquake/201103-eastjapan/ weather/data/radar-20110311/7.html, date of last access 20 September 2011).

\subsubsection{Japan}

10-13 March 2011. On 10 and 11 March 2011, the north of Honshu Island was located in air mass outflow from the Asian continent south and behind of a cyclone centered east of Kamchatka. The first emissions from FD-NPP were therefore transported to the eastsoutheast and over the North Pacific Ocean. The top left panels in Fig. 13 and Fig. 14 show, respectively, the ${ }^{133} \mathrm{Xe}$ and ${ }^{137} \mathrm{Cs}$ total atmospheric columns on 12 March at 06:00 UTC, superimposed by $850 \mathrm{hPa}$ geopotential. A comparison of the ${ }^{133} \mathrm{Xe}$ and ${ }^{137} \mathrm{Cs}$ distributions shows that the leading part of the ${ }^{133} \mathrm{Xe}$ plume is much stronger compared to the ${ }^{137} \mathrm{Cs}$ plume, a result mainly of the earlier start of ${ }^{133} \mathrm{Xe}$ emissions. On $12 \mathrm{March}$, a highpressure ridge had started to form behind the low to the northeast and as the ridge travelled eastward, the winds at FDNPP changed from WNW to SW. For a few hours around 18:00 UTC on 12 March the coastal areas north of FD-NPP 


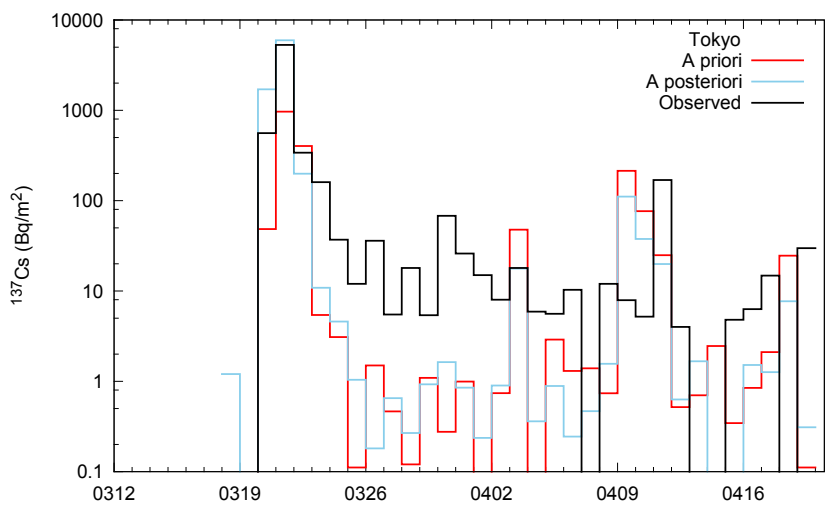

Fig. 12. Time series of observed (black line) and simulated daily ${ }^{137}$ Cs deposition in Tokyo, based on a priori (red line) and a posteriori (blue line) emissions.

were affected by the radioactive plume but deposition of radioactive material was limited because no precipitation fell at that time. Furthermore, ${ }^{137} \mathrm{Cs}$ emissions were still an order of magnitude lower than on 13 and 14 March. Therefore, this brief episode had little effect on Japanese land areas and winds over northern Honshu were again westerly on 13 March, transporting the FD-NPP plume away from Japan.

14 March 2011. On 14 March, a cyclone developed over southern Japan, which was linked to a larger cyclone northeast of Hokkaido. The precipitation over the Pacific Ocean associated with the frontal system of the larger cyclone is quite different in the ECMWF and GFS analyses. The ECMWF model has strong precipitation almost perfectly aligned with the radioactive plume emanating from FD-NPP at 12:00-15:00 UTC on 14 March. The GFS frontal precipitation is located slightly further to the south and, thus, the northern edge of the plume experiences relatively little scavenging. Plots of Japanese precipitation radar data suggest that the GFS view is more realistic and that in reality the front was probably placed even further to the south, but this is not fully conclusive because of the limited range of the radar data over the North Pacific Ocean. To examine the impact this has on ${ }^{137} \mathrm{Cs}$ concentrations and deposition during this important period with very high emissions, we made a model run using ECMWF data but applying the same source term as derived with the GFS reference data. Comparing the two simulations, we found that the deposition using the ECMWF data was $22 \%$ larger on 13-14 March than when using the GFS data, with differences being particularly large in our nested domain where they were $34 \%$ on average. This has large consequences for the intercontinental transport of ${ }^{137} \mathrm{Cs}$, as the weaker scavenging with GFS data left more ${ }^{137} \mathrm{Cs}$ in the atmosphere and, consequently, the GFS-FLEXPART simulations produced higher ${ }^{137} \mathrm{Cs}$ concentrations over North America and Europe than the ECMWF-FLEXPART simulations. The measurement data in North America and Europe are in better agreement with the GFS-FLEXPART results.
15 March 2011. The smaller cyclone over Honshu developed rapidly on 15 March, and the FD-NPP plume got caught in its circulation system. It was transported to the south at 18:00 UTC on 14 March, to the southwest six hours later, and back to the north and finally east from about 06:00 UTC on 15 March. The plume covered large parts of centraleastern Honshu and crossed over Tokyo and other major population centers before it left Japan towards the northeast around 18:00 UTC on 15 March. Figure 15 (top panel) shows the ${ }^{137} \mathrm{Cs}$ surface concentrations at 06:00 UTC on 15 March when precipitation had just started, and Fig. 15 (bottom panel) shows the total ${ }^{137} \mathrm{Cs}$ deposition and precipitation amount on 15 March. The cyclone produced a few millimeters of rain in areas on Honshu Island engulfed by the FD-NPP plume, which led to ${ }^{137} \mathrm{Cs}$ washout. Precipitation was strongest $(6 \mathrm{~mm})$ near FD-NPP, leading to high simulated deposition amounts of up to nearly $1000 \mathrm{kBq} \mathrm{m}^{-2}$ in the vicinity of FD-NPP. Tokyo is located just outside of the area with large deposition. Radar data suggests that the precipitation from the GFS model was spatially too smooth and widespread compared to real precipitation patterns. For instance, there was no rain in Tokyo directly, but it did snow in the mountainous areas surrounding the Kanto plain. Thus, our ${ }^{137} \mathrm{Cs}$ deposition may be spatially too extensive and, on the other hand, cannot capture local maxima. This is to be expected, given the global meteorological input data to our simulations.

Our simulation suggests that this was the main deposition event over Japan for the entire duration of the disaster. It was due to an unfortunate combination of three factors: (1) the highest emissions of the entire duration of the accident occurred during 14-15 March, (2) the winds transported these emissions over Japan, and (3) precipitation occurred over eastern Japan. Luckily, it did not rain when - according to our simulation - the highest concentrations were advected over Tokyo and other major Japanese cities, saving these places from much higher ${ }^{137} \mathrm{Cs}$ deposition.

The actual severity of this episode is still uncertain, as the sensitivity tests in Sect. 4.2.3 have shown that the emissions on 14-15 March are sensitive to the choice of input data for the inversion. To be matched by the model, the global ${ }^{137} \mathrm{Cs}$ monitoring data require much higher emissions than the Japanese data in this case. As a consequence, the reference inversion which includes the global data, overestimates the concentrations at most Japanese stations. At Tokai-mura (top panel in Fig. 10), the mismatch is particularly strong as peak concentrations are nearly a factor of four too high and the duration of the episode is too long. At Wako, Tsukuba and Chiba sites, the overestimate is consistently a factor of about 2.5, whereas at Takasaki the model underestimates by a factor of three. Qualitatively, our model seems to capture independent ${ }^{137} \mathrm{Cs}$ measurements made in Tokyo and shown in Winiarek et al. (2012) rather well. Unfortunately, virtually no deposition measurements exist for this event. A single sample taken at Tokai-mura - the same site where air 

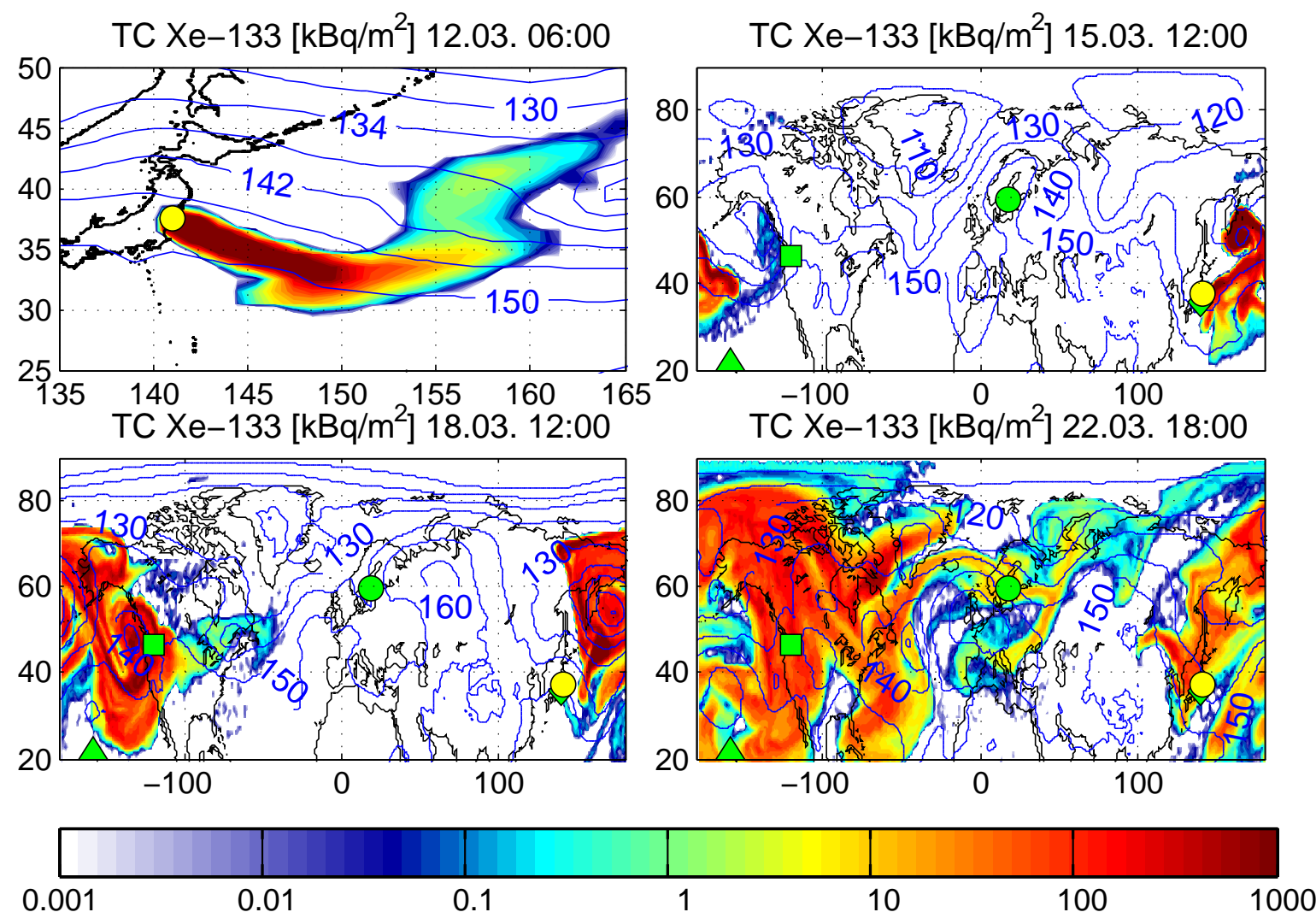

Fig. 13. Simulated total atmospheric columns of ${ }^{133} \mathrm{Xe}$ (color shading) and geopotential at $850 \mathrm{hPa}$ from GFS (blue isolines) at 06:00 UTC on 12 March (upper left panel), 12:00 UTC on 15 March (upper right panel), 12:00 UTC on 18 March, and 18:00 UTC on 22 March. (Hawaii) with a green triangle, Richland (USA) with a green square, and Stockholm (Sweden) with a green circle.

concentrations are strongly overestimated - from 15 March 03:00 UTC to 16 March 03:00 UTC shows a deposition of $830 \mathrm{~Bq} \mathrm{~m}^{-2}$, while the model gives $9660 \mathrm{~Bq} \mathrm{~m}^{-2}$. This large discrepancy may partly be caused by the spatial variability of the precipitation. In fact, we will present evidence later that this episode indeed caused most of the ${ }^{137} \mathrm{Cs}$ deposition at least in the vicinity of FD-NPP. Nevertheless, it seems that overall our model overestimates the impact of this episode in Japan, either due to a too high emission peak during the episode, or due to the coarse model resolution.

16-26 March 2011. Between 16 and 19 March, an anticyclone passed from west to east over southern Japan. Westerly winds between this anticyclone and a low pressure center near Kamchatka channeled the plume from FD-NPP again towards the North Pacific. However, on 20-21 March, a lowpressure trough passed over Japan, which separated the anticyclone from the Siberian High to the west, as can be seen by isolines of geopotential at $925 \mathrm{hPa}$ (Fig. 16, blue lines in left and middle panel). This trough spawned a cyclone at its southern tip over Honshu Island which had an extensive frontal system and caused strong precipitation over southern Honshu (Fig. 16, red isolines in right panel). While all ${ }^{133} \mathrm{Xe}$ had leaked out from FD-NPP reactor units earlier, emissions of ${ }^{137} \mathrm{Cs}$ showed a major peak on 19 March, probably from the spent-fuel pool in unit 4 . As winds veered from westerly to easterly direction late on 19 March, emissions from that day were brought back to Japan, in addition to ongoing emissions from FD-NPP. Consequently, the plume penetrated inland and, at 16:00 UTC on 20 March it covered large areas of eastern Honshu Island between 35 and $40^{\circ} \mathrm{N}$ (Fig. 16, left panel). On 21 March at 06:00 UTC, northeasterly winds prevailed at the edge of the extended Siberian High and the FD-NPP plume was transported directly across Tokyo and even further south to Shizuoka prefecture (Fig. 16, middle panel), while the cut-off cyclone was located just southwest of Tokyo. There, frontal precipitation led to particularly strong scavenging, and also Tokyo received an elevated ${ }^{137} \mathrm{Cs}$ deposition on 21 March (see Fig. 12; notice the good agreement between the simulated and observed ${ }^{137} \mathrm{Cs}$ deposition in Tokyo for this event). Transport of the FDNPP plume to the southwest and precipitation persisted until 12:00 UTC on 22 March. Total ${ }^{137}$ Cs deposition from 20 22 March was considerable for large parts of eastern Honshu Island (Fig. 16, right panel) but the maximum deposition values were about one order of magnitude smaller than those simulated during the 15 March event when emissions 

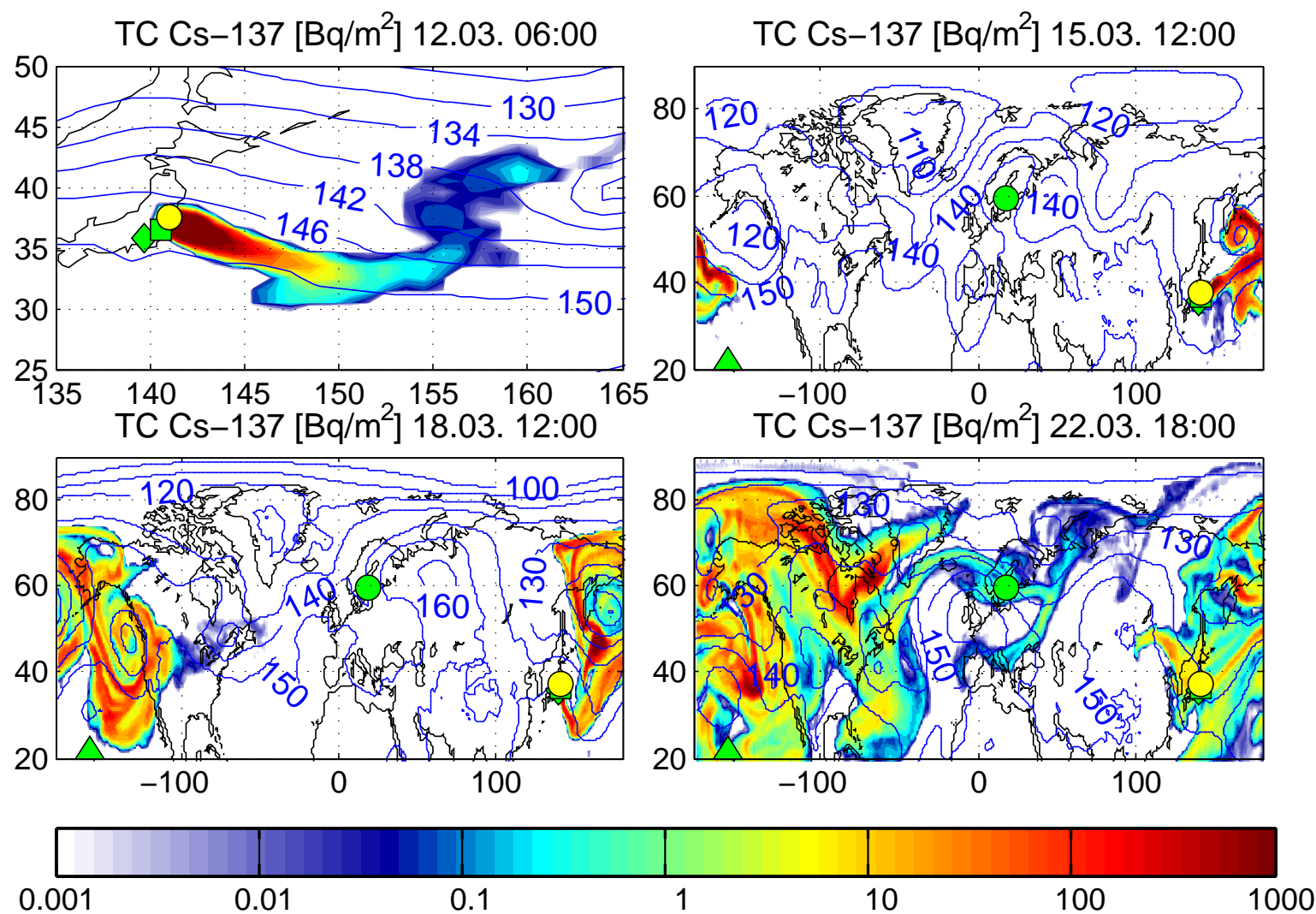

Fig. 14. Simulated total atmospheric columns of ${ }^{137} \mathrm{Cs}$ (color shading) and geopotential at $850 \mathrm{hPa}$ from GFS (blue isolines) at $06: 00 \mathrm{UTC}$ on 12 March (upper left panel), 12:00 UTC on 15 March (upper right panel), 12:00 UTC on 18 March, and 18:00 UTC on 22 March. The location of FD-NPP is shown with a yellow circle, the air sampling site Tokai-mura with a green square, the deposition monitoring site in Tokyo with a green diamond, and the air sampling station on Oahu (Hawaii) with a green triangle, and Stockholm with a green circle.

were higher. During the following days, until 26 March at 12:00 UTC, the plume veered around, with most of the emissions being transported towards the Pacific Ocean but occasionally overpassing coastal areas both to the south and north of FD-NPP.

\subsubsection{Hemispheric transport}

During the accident events, ${ }^{133} \mathrm{Xe}$ and ${ }^{137} \mathrm{Cs}$ from FD-NPP were dispersed throughout the Northern Hemisphere and eventually also reached the Southern Hemisphere. A first radionuclide cloud ahead of the main plume was transported quickly across the North Pacific at low altitudes in a steady westerly flow and arrived in western North America on 15 March (upper right panel in Fig. 13). This part contained only ${ }^{133} \mathrm{Xe}$ and cannot be seen in a corresponding map for ${ }^{137} \mathrm{Cs}$ (upper right panel in Fig. 13) because the ${ }^{137} \mathrm{Cs}$ emissions started later. This first radioactive cloud only skimmed along the North American seaboard, because a large cyclone over the Eastern Pacific Ocean produced a southerly flow along the coastline. It was nevertheless detected at Richland (Fig. 8, top panel).
The main plume was at that time still far from the coast. A vertical cross section showing ${ }^{133} \mathrm{Xe}$ concentrations along $165^{\circ} \mathrm{N}$ at 12:00 UTC on 15 March (Fig. 17) shows that south of $40^{\circ} \mathrm{N}$, the plume was transported near the surface, while further north it had been lifted to the middle and upper troposphere. This is a typical feature of pollution transport across the North Pacific (Stohl et al., 2002). The lifting in warm conveyor belts associated with midlatitude cyclones produces large amounts of precipitation (Wernli and Davies, 1997; Eckhardt et al., 2004). The associated strong in-cloud scavenging makes the lifted parts of the radioactive cloud relatively poor in ${ }^{137} \mathrm{Cs}$ relative to ${ }^{133} \mathrm{Xe}$ (compare upper right panels in Figs. 13 and 14).

The main part of the radioactive cloud entered western North America on 17-18 March and could be detected at monitoring sites there (see Fig. 8). On 18 March at 12:00 UTC (lower left panels in Fig. 13 and Fig. 14), high total column loadings of both ${ }^{133} \mathrm{Xe}$ and ${ }^{137} \mathrm{Cs}$ can be found over the eastern Pacific Ocean and western North America. This part of the cloud was relatively rich in ${ }^{137} \mathrm{Cs}$ because it was still close to the surface south of $50^{\circ}$. The high-altitude head of the cloud with lower column values of ${ }^{137} \mathrm{Cs}$ had 
already arrived over the North Atlantic. At the same time, the radioactive cloud penetrated the subtropics and arrived at Hawaii on 19 March (see also Fig. 10).

Emissions from FD-NPP first arrived over Europe on 20 March, however only at high altitudes. Surface measurements at Stockholm revealed enhanced ${ }^{133} \mathrm{Xe}$ concentrations first on 22 March (bottom panel in Fig. 8). A map of the simulated surface concentrations of ${ }^{133} \mathrm{Xe}$ (Fig. 18) for $22 \mathrm{March}$ shows that all of western North America was engulfed by the FD-NPP plume, as well as parts of eastern North America and eastern Asia. At that time, Europe was still free of enhanced ${ }^{133} \mathrm{Xe}$ at the surface, except for an isolated ${ }^{133} \mathrm{Xe}$ cloud over Scandinavia. Transport movies show that the contaminated air had been transported in the middle and upper troposphere and descended south of Iceland, just $12 \mathrm{~h}$ before arriving over Scandinavia. A comparison of total columns of ${ }^{133} \mathrm{Xe}$ and ${ }^{137} \mathrm{Cs}$ shows that this air is predicted to be rich in ${ }^{133} \mathrm{Xe}$ but relatively poor in ${ }^{137} \mathrm{Cs}$, due to wet scavenging during uplift (lower right panels in Figs. 13 and 14). The measurements (see Fig. 10) show that the ${ }^{137}$ Cs concentrations were even lower than predicted, suggesting that the model underestimated the wet scavenging in this case.

The total column plots (lower right panels in Figs. 13 and 14) show that on 22 March, contaminated air from FDNPP had circled the entire Northern Hemisphere and had reached both the tropics as well as the polar regions. Even though enhanced surface concentrations were still limited to smaller parts of the Northern Hemisphere (Fig. 18), this changed quickly. In April all measurement stations recorded an enhanced (but due to radioactive decay, decreasing) background of ${ }^{133} \mathrm{Xe}$ caused by the FD-NPP emissions, indicating the transition to complete dispersion in the Northern Hemisphere (see Stohl et al., 2012). Even the Australian station Darwin started recording enhanced ${ }^{133} \mathrm{Xe}$ concentrations in April, indicating penetration of radioactive contamination into the Southern Hemisphere.

Total deposition. Figure 19 shows maps of total deposition of ${ }^{137} \mathrm{Cs}$ in Japan and globally. The highest FD-NPP deposition values of about $1000 \mathrm{kBq} \mathrm{m}^{-2}$ occur in a plume stretching from FD-NPP to the northwest. The orientation of this simulated plume is exactly as found by aerial surveys of ${ }^{137} \mathrm{Cs}$ surface deposition inside a radius of about $100-130 \mathrm{~km}$ around FD-NPP using several aircraft between 6 April and 26 May 2011 (MEXT, 2011). The airborne measurements show that along the main plume axis, ${ }^{137} \mathrm{Cs}$ deposition values greater than $1000 \mathrm{kBq} \mathrm{m}^{-2}$ extend about $50 \mathrm{~km}_{\text {from } \mathrm{FD}-}$ NPP. This is consistent with our results both in terms of deposition magnitude and extension, but a more detailed comparison is difficult because the measured deposition is spatially highly variable on scales of a few kilometers, and this cannot be resolved by our model. Since the modeled ${ }^{137} \mathrm{Cs}$ total deposition is mainly due to the deposition event on 15 March, the agreement of deposition patterns with the airborne observations suggests that 15 March was correctly identified with our model as the strongest deposition episode. Given that al-
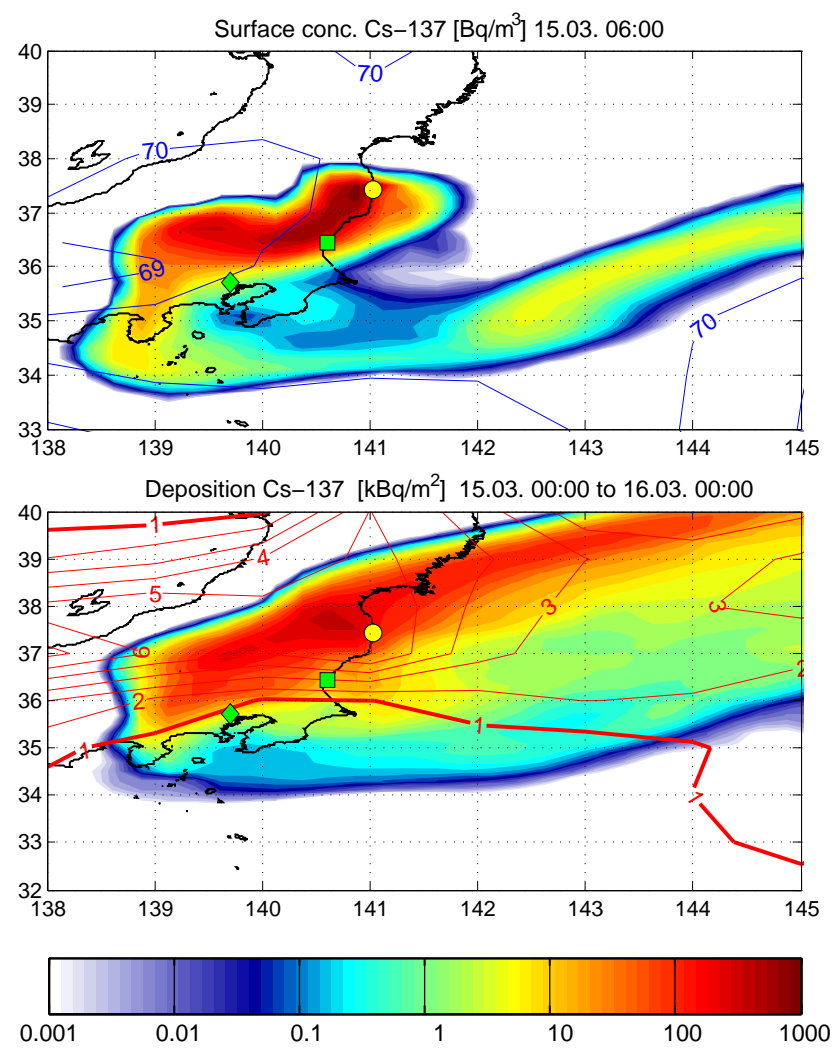

Fig. 15. Simulated surface concentrations of ${ }^{137} \mathrm{Cs}$ (color shading) and $925 \mathrm{hPa}$ geopotential from GFS (blue isolines) at 06:00 UTC on 15 March (upper panel), as well as total ${ }^{137} \mathrm{Cs}$ deposition (color shading) and accumulated precipitation from 00:00-24:00 UTC on 15 March (lower panel). The location of FD-NPP is shown with a yellow circle, the air sampling site Tokai-mura with a green square, and the deposition monitoring site in Tokyo with a green diamond.

most no deposition measurements were made on 15 March, this is an important confirmation.

Our maps of total ${ }^{137} \mathrm{Cs}$ deposition are quite different from those presented by Yasunari et al. (2011), which show smaller deposition amounts. This can be explained by the fact that Yasunari et al. (2011) only had sufficient deposition data available for their study starting from 20 March, and that does not include the most severe deposition event according to our study, on 15 March. In fact, their Fig. 2 is quite similar to our deposition map for 20-22 March (left panel in Fig. 16).

To put our findings into perspective, a comparison with the Chernobyl disaster is quite interesting. Following the Chernobyl accident, ${ }^{137} \mathrm{Cs}$ deposition values exceeding $1000 \mathrm{kBq} \mathrm{m}^{-2}$ were observed in two areas, namely in the exclusion zone around Chernobyl NPP/Prypjat and north of the city of Gomel in Belarus (see deposition maps in UNSCEAR, 2000b). For the FD-NPP accident, the land areas receiving such high deposition values are smaller, but they are still extensive. Another comparison of interest is with the ${ }^{137} \mathrm{Cs}$ deposition in the extratropical Northern Hemisphere still present due to past nuclear testing, about $1-2 \mathrm{kBq} \mathrm{m}^{-2}$ 

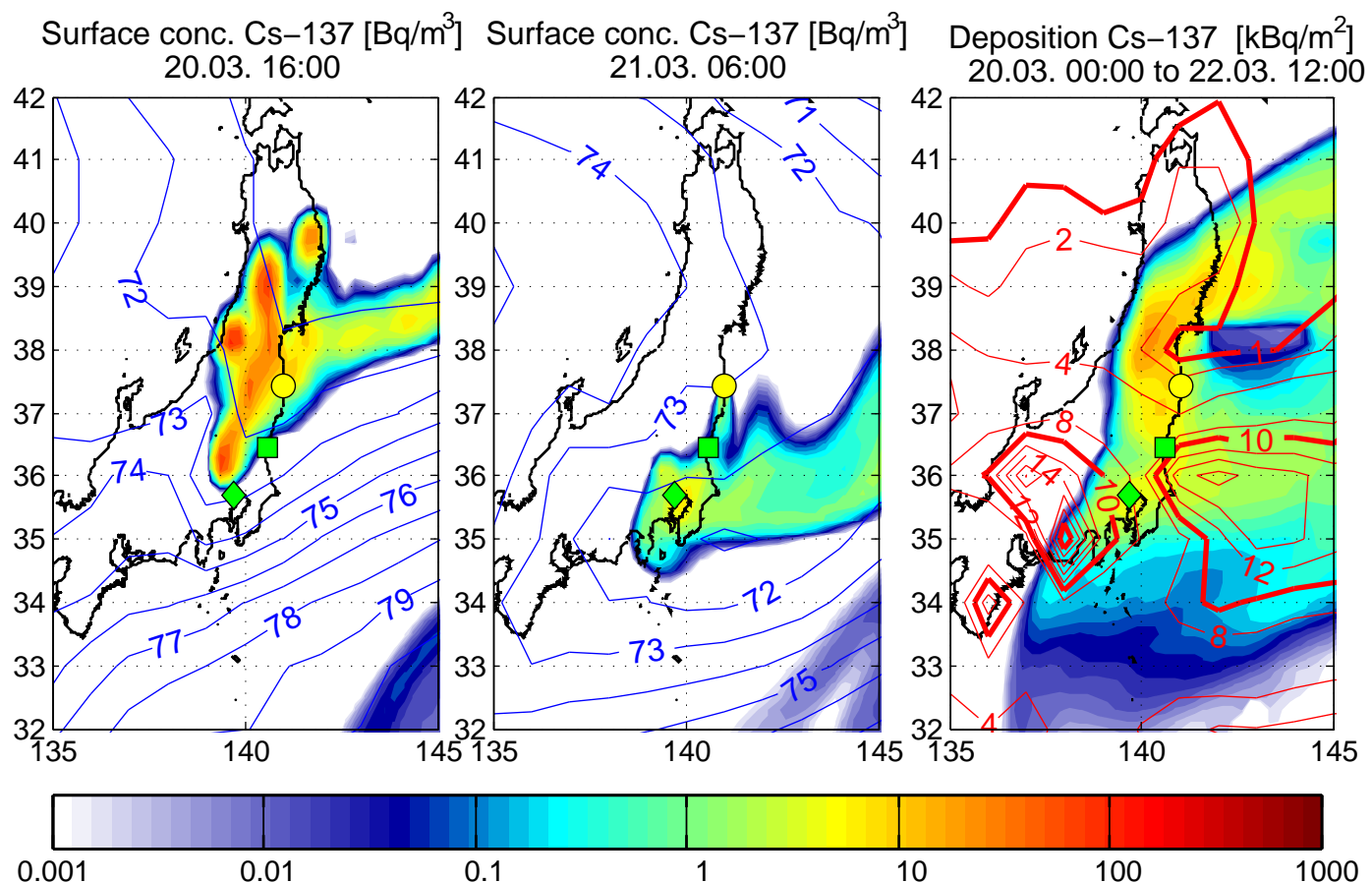

Fig. 16. Simulated surface concentrations of ${ }^{137} \mathrm{Cs}$ at 16:00 UTC on 20 March (color shading) and $925 \mathrm{hPa}$ geopotential from GFS (blue isolines) at 15:00 UTC on 20 March (left panel) and at 06:00 UTC on 21 March (middle panel), as well as total ${ }^{137}$ Cs deposition (color shading) and accumulated precipiation (in mm, red lines) from 00:00 UTC on 20 March to 12:00 UTC on 22 March (right panel). The location of FD-NPP is shown with a yellow circle, the air sampling site Tokai-mura with a green square, and the deposition monitoring site in Tokyo with a green diamond.

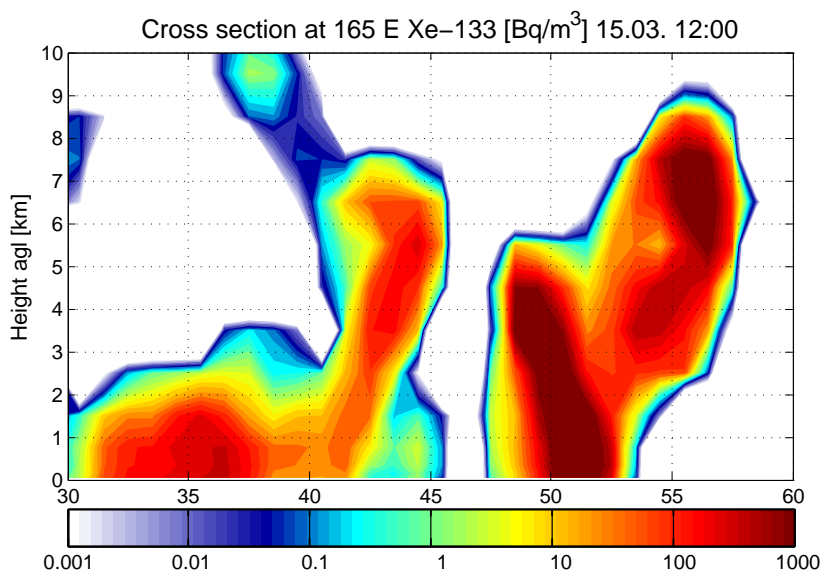

Fig. 17. Vertical cross section along $165^{\circ} \mathrm{E}$ through the model output for ${ }^{133} \mathrm{Xe}$ at 12:00 UTC on 15 March.

(UNSCEAR, 2000a). That value is exceeded by deposition from FD-NPP over large parts of Honshu Island and the western Pacific Ocean. However, deposition of FD-NPP ${ }^{137} \mathrm{Cs}$ emissions over other parts of Asia, North America and Europe is minor compared to this pre-existing background.

To determine the deposition amounts in Japan and other regions, we combined our gridded accumulated deposition fields on 20 April at 00:00 UTC (decay-corrected for that time) with a land-sea mask. This analysis accounts for more than $90 \%$ of the ${ }^{137} \mathrm{Cs}$ emissions until 20 April, with the rest still residing in the atmosphere and small amounts destroyed by radioactive decay. We find that Japanese land areas received $6.4 \mathrm{PBq}$, or $18 \%$ of the total ${ }^{137} \mathrm{Cs}$ deposition until 20 April. The relative fraction deposited in Japan is quite similar to the $22 \%$ reported by Morino et al. (2011), although their absolute values are smaller because of lower emissions used. Only $0.7 \mathrm{PBq}$, or $1.9 \%$ of the total ${ }^{137} \mathrm{Cs}$ deposition occurred over land areas other than Japan, while the remaining $80 \%$ were deposited in the oceans.

\section{Conclusions}

In this study, we estimated the total releases of the radioactive isotopes ${ }^{133} \mathrm{Xe}$ and ${ }^{137} \mathrm{Cs}$ as well as their temporal emission patterns from the damaged Fukushima Dai-ichi nuclear power plant (FD-NPP) in March and April 2011. The estimate is based on an inverse modeling method, using the transport model FLEXPART and a large number of available concentration and deposition measurements in Japan, North America, Europe, and a few other locations. Despite the significant uncertainties in simulations as well as measurements, the inversion method was able to produce 


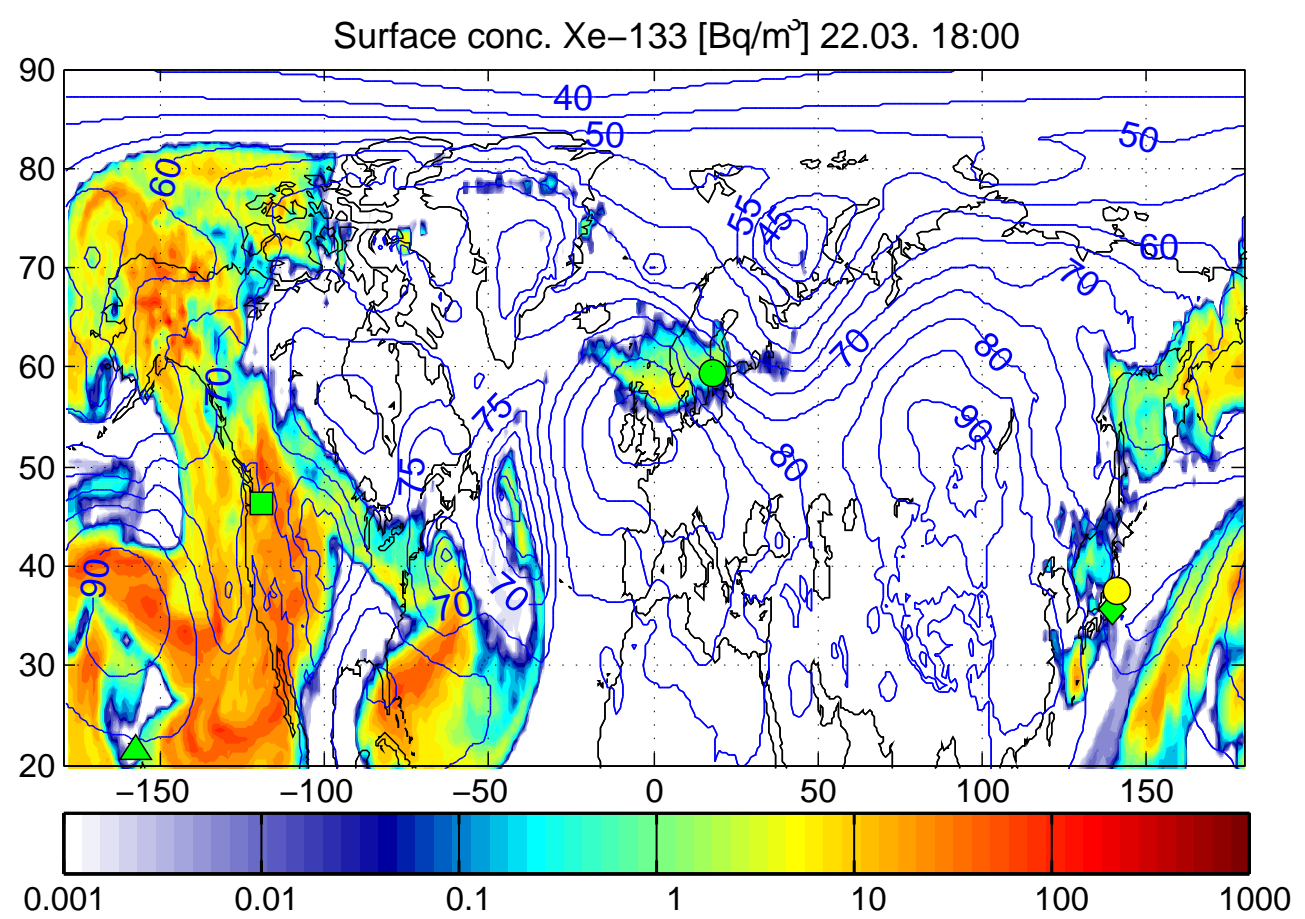

Fig. 18. Surface concentrations of ${ }^{133} \mathrm{Xe}$ (color shading) and geopotential at $925 \mathrm{hPa}$ (blue isolines) at 18:00 UTC on $22 \mathrm{March}$. In the lower panel, the stations Oahu (Hawaii) and Stockholm (Sweden) are marked with a green triangle and a green circle, respectively.

model results that are largely consistent with the measurement data.

Regarding the noble gas ${ }^{133} \mathrm{Xe}$, it is almost certain that the accumulated inventory of the reactor units 1-3 was completely set free into the atmosphere between 11 and 15 March. The study indicates a total release of 15.3 (uncertainty range 12.2-18.3) EBq, more than the estimated inventory of $12.4 \mathrm{EBq}{ }^{133} \mathrm{Xe}$. We explain this with the additional decay of ${ }^{133} \mathrm{I}$ into ${ }^{133} \mathrm{Xe}$, which would effectively increase the estimated inventory to $14.4 \mathrm{EBq}{ }^{133} \mathrm{Xe}$. This release is more than a factor of two higher than the Chernobyl ${ }^{133} \mathrm{Xe}$ source term and most likely the largest radioactive noble gas release in history. There is also strong evidence that the start of the release occurred early, before the first active venting was made. This early onset of emissions is interesting and might indicate some structural damage to the reactor units by the earthquake.

Regarding ${ }^{137} \mathrm{Cs}$, the inversion results indicate a total emission of $36.6(20.1-53.1) \mathrm{PBq}$, or about $43 \%$ of the estimated Chernobyl emission. This means that nearly $2 \%$ of the available inventory of the reactor cores in units 1-3 and the spent-fuel pool in unit 4 was discharged into the atmosphere. The inversion strongly increased the emissions early on 12 March, around the time when the first explosion occurred in unit 1 . These early emissions were estimated lower by the Japanese authorities, but are in accordance with the first estimates published by Central Institute for Meteorology and Geodynamics (2011). The highest release rates occurred on 14 March, when hydrogen explosions occurred in reactor units 3 and 4 and, presumably, unit 2. We also find unexpectedly high ${ }^{137} \mathrm{Cs}$ emissions from $16-19$ March, which suddenly dropped by orders of magnitude when spraying of water on the spent-fuel pool of unit 4 started. Thus, we believe that these high emissions are related to the degraded fuel in the spent-fuel pool of unit 4 , and this result would also confirm that the spraying was an effective countermeasure at least in this case. Between 19 March and 10 April, episodic but generally decreasing emissions were found.

The winds transported the FD-NPP emissions towards the Pacific Ocean most of the time, while Japan was affected only occasionally. While this seemed like a relatively fortunate situation for Japan during the accident event, a different picture emerges from our detailed analysis. Exactly during and following the period of the highest ${ }^{137} \mathrm{Cs}$ emission rates on 14 and 15 March, the FD-NPP plume was advected towards Japan and affected large areas in the east of Honshu Island. The advection towards Japan was triggered by a developing cyclone, which produced precipitation on 15 March, leading to the deposition of large fractions of the airborne ${ }^{137} \mathrm{Cs}$ over Japanese land. However, the situation could have been even much worse, as fortunately no rain occurred at the time when the FD-NPP plume was transported over Tokyo. Our model seems to overestimate the impact of this episode in Japan, either due to an emission overestimate on 14-15 March, or insufficient model resolution. 

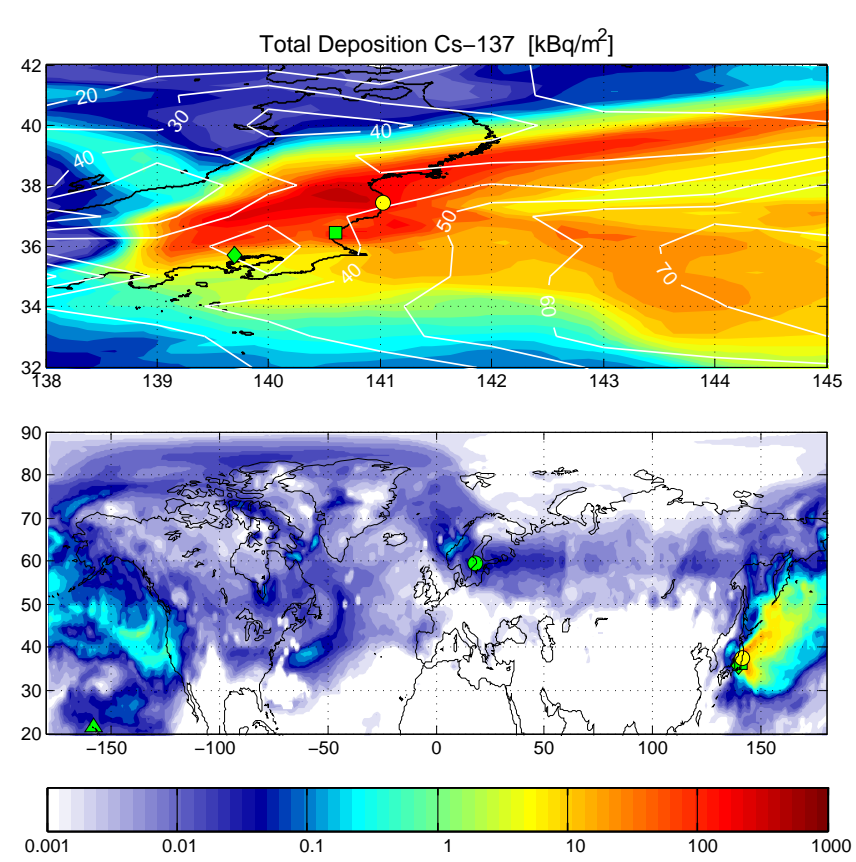

Fig. 19. Maps of total deposition of ${ }^{137} \mathrm{Cs}$ until 20 April 00:00 UTC, for Japan (upper panel) and the global domain (lower panel). Superimposed on the upper panel is the total precipitation from GFS for the same time period. The location of FD-NPP is shown with a yellow circle, the air sampling site Tokai-mura with a green square, and the deposition monitoring site in Tokyo with a green diamond. In the lower panel, the stations Oahu (Hawaii) and Stockholm (Sweden) are marked with a green triangle and a green circle, respectively.

During a second episode from 20-22 March, even larger areas of Honshu were covered by the FD-NPP radioactive cloud, from Shizuoka prefecture in the south to areas north of FD-NPP. Strong frontal precipitation nearly completely cleansed the atmosphere of ${ }^{137} \mathrm{Cs}$ and again produced strong deposition of this radionuclide over Honshu, including Tokyo. This episode again followed a period of high (though fortunately not as high as on $14-15$ March) ${ }^{137}$ Cs emission fluxes on 19 March, which were transported to Japan on 20 March. There were a few other periods when the FD-NPP plume was advected over land, but the areas affected were smaller and the emissions lower, resulting in minor contamination compared to 15 and 20-21 March.

The emissions from FD-NPP were quickly dispersed in the entire Northern Hemisphere. Already on 15 March, a first isolated ${ }^{133} \mathrm{Xe}$ cloud reached western North America, followed by the arrival of high concentrations of both ${ }^{133} \mathrm{Xe}$ and ${ }^{137} \mathrm{Cs}$ on 19 March. Europe was first reached on 22 March by an air mass rich in ${ }^{133} \mathrm{Xe}$ but relatively poor in ${ }^{137} \mathrm{Cs}$, which had been lifted in a frontal system over the North Pacific, was transported aloft and descended again over the North Atlantic shortly before reaching Northern Europe. Precipitation associated with the frontal lifting had removed most of the ${ }^{137} \mathrm{Cs}$, but the noble gas ${ }^{133} \mathrm{Xe}$ remained in the air mass. Higher ${ }^{137} \mathrm{Cs}$ concentrations reached $\mathrm{Eu}-$ rope at the end of March. By middle of April, ${ }^{133} \mathrm{Xe}$ was fairly uniformly distributed in the middle latitudes of the entire Northern Hemisphere and was for the first time also measured in the Southern Hemisphere (Darwin station, Australia).

A quantitative analysis of the model output shows that $18 \%$ of the total ${ }^{137} \mathrm{Cs}$ deposition until 20 April occurred over Japanese land. Only $0.7 \mathrm{PBq}$, or $1.9 \%$ of the total deposition were received by land areas other than Japan, while the remaining $80 \%$ were deposited in the oceans.

\section{Needs for open data policy and further research}

While we have collected measurement data from a variety of sources, virtually none of these data sets is publicly available, and there are probably more useful data sets that were not accessible to us. Institutions having produced relevant measurement data should make them freely available. A central data repository should be created where these data are being stored, quality assured, reformatted to a common format and made available to the general public. This will allow considerable improvements of the source terms in the future.

We have derived the source terms for two important radionuclides. However, this needs to be done also for other radionuclides, notably iodine- 131 .

We have used a global model for our study. Future studies should apply a nesting approach, where high resolution can be achieved over Japan. This would facilitate a more accurate simulation of radionuclide transport over Japan, which is important for assessing the impacts on human population. Importantly, this would also allow more accurate inverse modeling since better use of the Japanese measurement data could be made with reduced model errors.

There is a need for planned atmospheric tracer experiments to evaluate and further improve dispersion models used in emergency applications, as argued recently by Galmarini et al. (2011). There is also a need for careful checking and improvement of washout parameterizations in atmospheric dispersion models. The data set used in this paper could be useful in that respect.

\section{Appendix A}

\section{Accident events at the different units}

\section{A1 Unit 1}

On 14:00 UTC, 11 March (less than $8 \mathrm{~h}$ after the station blackout) increased radiation was observed in the turbine hall, indicating that at least noble gases must have started to leak into the environment. At the same time, pressure built up 
inside the containment and it is reported that between 00:15 and $01: 17$ on 12 March relieve valves were opened, probably giving rise to large releases. It is reported that at 05:30 on 12 March the venting was finished. We assume that a large part of the release has occured by then. At 06:36, the unit 1 hydrogen explosion (which was the first one) happened, obviously from hydrogen that had entered various reactor building compartments during the venting, or through leaks. The containment pressure had dropped by 09:00 so that we assume the release was largely over at that time. Emissions would likely continue at a lower rate through various leaks and at some point in time possibly also from the spent-fuel pond which after the explosion was directly exposed to the environment. On 14 March, a secondary pressure maximum in the containment was reported, possibly indicating another, minor, peak in the emissions.

\section{A2 Unit 2}

Unit 2 is of a newer design than unit 1 and was able to withstand the station blackout somewhat longer. The first venting for this unit is reported at 02:00 UTC on 13 March, with unclear success, and the first time of confirmed open safety relief valves is 09:00 UTC on 14 March. Radiation measurements in the wet well and dry well (reactor compartments below the pressure vessel, inside the containment) jumped up about an hour later, probably indicating core melt, and also MELCOR calculations give fuel melting for this time, as well as noble gas release. Thus we think that noble gases have been vented more or less completely at this time. At 15:00 UTC, another venting of the dry well was performed, and a hydrogen explosion is suspected to have damaged the wet well at 21:14. Large releases appear likely. On 15 March, 21:00 UTC, pressure vessel and dry well were at ambient pressure, indicating the lack of any efficient barrier. The bulk of the discharge should have occurred by that time, but similar to unit 1, weak releases may continue. Between 26 March and April 19 a secondary temperature increase in the RPV was reported, possibly associated with somewhat increased release.

\section{A3 Unit 3}

For unit 3, the first venting operation, through the wet well, is reported for 23:41 UTC on 11 March. This should already have released noble gases. About $24 \mathrm{~h}$ later, after observed increase in the suppression chamber pressure, a second venting of about $20 \mathrm{~min}$ was reported. On 13 March at 20:20 the safety relief valves were reported open, and MELCOR indicates pressure vessel failure around this time. Six hours later, 02:00 UTC on 14 March, a very strong hydrogen explosion occurred, severely damaging the upper part of the reactor building and scattering debris. The Report indicates end of venting at 03:00 UTC. This should have ended the large release. However, until 20 March, various opening and closing operations of the valves are reported which may have given rise to intermittent emission peaks on top of the slower discharge which is expected similar to unit 1. Finally, between 1 April and 24 some secondary increase in pressure vessel temperatures was reported.

\section{A4 Unit 4}

Little information has been published on the spent fuel pond of unit 4 (which was the most critical one due to the high loading). Its water temperature was reported as $84^{\circ} \mathrm{C}$ on 13 March, 19:00 UTC. At such temperatures some release of radionuclides is already likely. On 14 March, 21:00 UTC, a major hydrogen explosion occurred in unit 4 . This may or may not have been caused by degraded fuel in the pond. It is reported that on 19 March, 23:21 UTC, spraying of water on the pool was started. Having no further information, we simply assumed a release fraction on the same order as for the reactor cores, less than $1 \%$ of the caesium inventory, which is thought to have mainly been released between hydrogen explosion and the start of water spraying.

\section{Supplement related to this article is available online at: http://www.atmos-chem-phys.net/12/2313/2012/ acp-12-2313-2012-supplement.zip.}

Acknowledgements. We would like to thank S. Furuta and M. Chino for providing ${ }^{137} \mathrm{Cs}$ concentration and deposition data from Tokai-mura; H. Haba for the Wako ${ }^{137} \mathrm{Cs}$ concentration data; K. Ungar and I. Hoffman for ${ }^{133}$ Xe data from Sidney and ${ }^{137} \mathrm{Cs}$ data from Ottawa, Canada; H. Miley for ${ }^{133}$ Xe data from Richland; S.-C. Hsu for data from Taiwanese stations; MEXT for providing the ${ }^{137} \mathrm{Cs}$ deposition data from all Japanese prefectures; colleagues from the Ro5 network for the Ro5 data; and all the researchers who produced the CTBTO measurement data. Y. Yokouchi helped locating the data from Tsukuba and Chiba. M. Takigawa made the on-site dose rate measurements available in a convenient format. The second author is grateful for discussions with staff of the Institute of Safety and Risk Sciences at BOKU. This work is partly a spin-off of the project SOGG-EA (Sources of Greenhouse Gases in East Asia) funded by the Norwegian Research Council. ECMWF and met.no granted access to ECMWF analysis data.

Edited by: H. Wernli

\section{References}

Andreev, I., Hittenberger, M., Hofer, P., Kromp-Kolb, H., Kromp, W., Seibert, P., and Wotawa, G.: Risks due to beyond design base accidents of nuclear power plants in Europe - the methodology of Riskmap, J. Hazard. Mater., 61, 257-262, 1998.

Becker, A., Wotawa, G., Ringbom, A., and Saey, P. R. J.: Backtracking of noble gas measurements taken in the aftermath of the announced October 2006 event in North Korea by means of PTS methods in nuclear source estimation and reconstruction, Pure Appl. Geophys., 167, 581-599, 2010. 
Bowyer, T. W., Biegalski, S. R., Cooper, M., Eslinger, P. W., Haas, D., Hayes, J. C., Miley, H. S., Strom, D. J., and Woods, V.: Elevated radioxenon detected remotely following the Fukushima nuclear accident, J. Environ. Radioact., 102, 681-687, 2011.

Brandt, J., Christensen, J. H., and Frohn, L. M.: Modelling transport and deposition of caesium and iodine from the Chernobyl accident using the DREAM model, Atmos. Chem. Phys., 2, 397-417, doi:10.5194/acp-2-397-2002, 2002.

Central Institute for Meteorology and Geodynamics (ZAMG): Accident in the Japanese NPP Fukushima: Spread of radioactivity/first source estimates from CTBTO data show large source terms at the beginning of the accident/weather currently not favourable/low level radioactivity meanwhile observed over U.S. East Coast and Hawaii, http://www.zamg.ac.at/docs/aktuell/ Japan2011-03-22_1500_E.pdf, last access: 28 September 2011.

Chino, M., Ishikawa, H., and Yamazawa, H.: SPEEDI and WSPEEDI: Japanese Emergency Response Systems to Predict Radiological Impacts in Local and Workplace Areas due to a Nuclear Accident, Radiat. Prot. Dosimetry, 50, 145-152, 1993.

Chino, M., Nakayama, H., Nagai, H., Terada, H., Katata, G., and Yamazawa, H.: Preliminary estimation of release amounts of ${ }^{131}$ I and ${ }^{137}$ Cs accidentally discharged from the Fukushima Daiichi nuclear power plant into the atmosphere, J. Nuc. Sci. Tech., 48, 1129-1134, 2011.

Davoine, X. and Bocquet, M.: Inverse modelling-based reconstruction of the Chernobyl source term available for long-range transport, Atmos. Chem. Phys., 7, 1549-1564, doi:10.5194/acp-71549-2007, 2007.

Devell, L., Güntay, S., and Powers, D. A.: The Chernobyl Reactor Accident Source Term: Development of a Consensus View, CSNI Report, Organisation for Economic Co-Operation and Development (OECD), OCDE/GD(96)12, 1995.

Eckhardt, S., Stohl, A., Wernli, H., James, P., Forster, C., and Spichtinger, N: A 15-year climatology of warm conveyor belts, J. Climate 17, 218-237, 2004.

Eckhardt, S., Prata, A. J., Seibert, P., Stebel, K., and Stohl, A.: Estimation of the vertical profile of sulfur dioxide injection into the atmosphere by a volcanic eruption using satellite column measurements and inverse transport modeling, Atmos. Chem. Phys., 8, 3881-3897, doi:10.5194/acp-8-3881-2008, 2008.

Furuta, S., Sumiya, S., Watanabe, H., Nakano, M., Imaizumi, K., Takeyasu, M., Nakada, A., Fujita, H., Mizutani, T., Morisawa, M., Kokubun, Y., Kono, T., Nagaoka, M., Yokoyama, H., Hokama, T., Isozaki, T., Nemoto, M., Hiyama, Y., Onuma, T., Kato, C., and Kurachi, T.: Results of the Environmental Radiation Monitoring Following the Accident at the Fukushima Daiichi Nuclear Power Plant - Interim Report (Ambient Radiation Dose Rate, Radioactivity Concentration in the Air and Radioactivity Concentration in the Fallout), Radiation Protection Department, Nuclear Fuel Cycle Engineering Laboratories, Tokai Research and Development Center, Japan Atomic Energy Agency, JAEA-Review 2011-035 (Draft), 2011.

Galmarini, S., Stohl, A., and Wotawa, G.: Fund experiments on atmospheric hazards, Nature, 473, p. 285, 2011.

Gauntt, R. O., Cole, R. K., Erickson, C. M., Gido, R. G., Gasser, R. D., Rodriguez, S. B., Young, M. F., Ashbaugh, S., Leonard, M., and Hill, A.: MELCOR Computer Code Manuals, Vol. 3: Demonstration Problems, Version 1.8.5 May 2001, Sandia National Laboratories, SAND2001-0929P, Albuquerque, USA,
2001.

Gudiksen, P. H., Harvey, T. F., and Lange, R.: Chernobyl source term, atmospheric dispersion, and dose estimation, Health Phys., 57, 697-706,1989.

Hartley, D. and Prinn, R.: Feasibility of determining surface emissions of trace gases using an inverse method in a threedimensional chemical transport model, J. Geophys. Res., 98, 5183-5197, 1993.

Hass, H., Memmesheimer, M., Geis, H., Jakobs, H. J., Laube, M., and Ebel, A.: Simulation of the Chernobyl radioactive cloud over Europe using the EURAD model, Atmos. Environ., 24A, 673$692,1990$.

Hertel, O., Christensen, J. Runge, E. H., Asman,W. A. H., Berkowicz, R., Hovmand, M. F., and Hov, O.: Development and testing of a new variable scale air pollution model - ACDEP, Atmos. Environ., 29, 1267-1290, 1995.

Hoffmann, W., Kebeasy, R., Firbas, P.: Introduction to the verification regime of the Comprehensive Nuclear-Test-Ban Treaty, Phys. Earth Planet. Inter., 113, 5-9, 2000.

Hsu, S.-C., Huh, C.-A., Chan, C.-Y., Lin, S.-H., Lin, F.-J., and Liu, S. C.: Hemispheric dispersion of radioactive plume laced with fission nuclides from the Fukushima nuclear event, Geophys. Res. Lett., 39, L00G22, doi:10.1029/2011GL049986, 2012.

Institut de Radioprotection et de Surete Nucleaire (IRSN): IRSN publishes assessment of radioactivity released by the Fukushima Daiichi Nuclear Power Plant (Fukushima I) through 22 March 2011, http://www.irsn.fr/EN/news/Documents/IRSN_ fukushima-radioactivity-released-assessment-EN.pdf, last access: 28 September 2011, 2011.

Kirchner, G., Bossew, P., and De Cort, M.: Radioactivity from Fukushima Dai-ichi in air over Europe; part 2: what can it tell us about the accident? J. Environ. Radioact. doi:10.1016/j.envrad.2011.12.016, in press, 2012.

Kristiansen, N. I., Stohl, A., Prata, A. J., Richter, A., Eckhardt, S., Seibert, P., Hoffmann, A., Ritter, C., Bitar, L., Duck, T. J., and Stebel, K.: Remote sensing and inverse transport modeling of the Kasatochi eruption sulfur dioxide cloud, J. Geophys. Res., 115, D00L16, doi:10.1029/2009JD013286, 2010.

Mahowald, N. M., Prinn, R. G., and Rasch, P. J.: Deducing $\mathrm{CCl}_{3} \mathrm{~F}$ emissions using an inverse method and chemical transport models with assimilated winds, J. Geophys. Res., 102, 28153-28168, 1997.

Masson, O., Baeza, A., Bieringer, J., Brudecki, K., Bucci, S., Cappai, M., Carvalho, F. P., Connan, O., Cosma, C., Dalheimer, A., D. Didier, G. Depuydt, L.E. De Geer, A. De Vismes, L. Gini, F. Groppi, K. Gudnason, R. Gurriaran, D. Hainz, Halldorsson, O., D. Hammond, O. Hanley, K. Holey, Zs. Homoki, A. Ioannidou, K. Isajenko, M. Jankovic, C. Katzlberger, M. Kettunen, R. Kierepko, R. Kontro, P.J.M. Kwakman, M. Lecomte, L. Leon Vintro, A.-P. Leppänen, B. Lind, G. Lujaniene, P. Mc Ginnity, C. Mc Mahon, H. Mala, S. Manenti, M. Manolopoulou, A. Mattila, A. Mauring, J.W. Mietelski, B. Mller, S.P. Nielsen, J. Nikolic, R.M.W. Overwater, S. E. Palsson, C. Papastefanou, I. Penev, M.K. Pham, P.P. Povinec, H. Ramebäck, M.C. Reis, W. Ringer, A. Rodriguez, P. Rulik, P.R.J. Saey, V. Samsonov, C. Schlosser, G. Sgorbati, B. V. Silobritiene, C. Söderström, R. Sogni, L. Solier, M. Sonck, G. Steinhauser, T. Steinkopff, P. Steinmann, S. Stoulos, I. Sykora, D. Todorovic, N. Tooloutalaie, L. Tositti, J. Tschiersch, A. Ugron, E. Vagena, A. Vargas, 
H. Wershofen, and Zhukova, O.: Tracking of airborne radionuclides from the damaged Fukushima Dai-Ichi nuclear reactors by European Networks, Environ. Sci. Technol., 45, 7670-7677, doi:10.1021/es2017158, 2011.

McMahon, T. A., and Denison, P. J.: Empirical atmospheric deposition parameters - a survey, Atmos. Environ., 13, 571-585, 1979.

Medici, F.: The IMS radionuclide network of the CTBT, Radiat. Phys. Chem., 161, 689-690, 2001.

MEXT (Ministry of Education, Culture, Sports, Science and Technology): Results of the 2nd Airborne Monitoring by the Ministry of Education, Culture, Sports, Science and Technology and the U.S. Department of Energy, online available at: http://radioactivity.mext.go.jp/en/1270/2011/06/ 1304797_0616e.pdf, last access: 25 September 2011.

Morino, Y., Ohara, T., and Nishizawa, M.: Atmospheric behavior, deposition, and budget of radioactive materials from the Fukushima Daiichi nuclear power plant in March 2011, Geophys. Res. Lett., 38, LOOG11, doi:10.1029/2011GL048689, 2011.

Nature News Blog: First estimates of total radioactive cesium and iodine emissions from Fukushima plant, http://blogs.nature.com/ news/2011/03/first_estimates_of_radioactive.html, last access: 28 September 2011, 2011.

Nuclear Energy Agency (NEA): Chernobyl: Assessment of Radiological and Health Impacts - 2002 Update of Chernobyl: Ten Years On, Organisation for Economic Co-Operation and Development (OECD) Publications, 155p., Paris, 2002.

Nuclear Emergency Response Headquarters, Government of Japan: Report of the Japanese Government to the IAEA Ministerial Conference on Nuclear Safety - The Accident at TEPCO's Fukushima Nuclear Power Stations, http://www.iaea. org/newscenter/focus/fukushima/japan-report/, last access: 7 October 2011.

Oak Ridge National Laboratory: SCALE: A Modular Code System for Performing Standardized Computer Analyses for Licensing Evaluations, ORNL/TM-2005/39, Version 5, Vols. I-III, April 2005, available from Radiation Safety Information Computational Center at Oak Ridge National Laboratory as CCC-725, 2005.

Saey, P. R. J., and de Geer, L.-E.: Notes on radioxenon measurements for CTBT verification purposes, Appl. Radiat. Isot., 63, 765-773, 2005.

Seibert, P.: Inverse modelling of sulfur emissions in Europe based on trajectories, In: Inverse Methods in Global Biogeochemical Cycles, edited by: Kasibhatla, P., Heimann, M., Rayner, P., Mahowald, N., Prinn, R. G., and Hartley, D. E., 147-154, Geophysical Monograph 114, American Geophysical Union, ISBN 0-87590-097-6, Washington, DC, USA, 2000.

Schulze, J., Auer, M., and Werzi, R.: Low level radioactivity measurement in support of the CTBTO, Appl. Radiat. Isot., 53, 2330, 2000.

Seibert, P., Kristiansen, N. I., Eckhardt, S., Prata A. J., Richter, A., and Stohl, A.: Uncertainties in the inverse modelling of sulphur dioxide eruption profiles, Nat. Haz. Risk, 2, 201-216, doi:10.1080/19475705.2011.590533, 2011.

Stohl, A., Hittenberger, M., and Wotawa, G.: Validation of the Lagrangian particle dispersion model FLEXPART against large scale tracer experiment data, Atmos. Environ., 32, 4245-4264, 1998.
Stohl, A., and Thomson, D. J.: A density correction for Lagrangian particle dispersion models, Bound.-Layer Meteorol. 90, 155167, 1999.

Stohl, A., Eckhardt, S., Forster, C., James, P., and Spichtinger, N.: On the pathways and timescales of intercontinental air pollution transport, J. Geophys. Res., 107, 4684, doi:10.1029/2001JD001396, 2002.

Stohl, A., Forster, C., Frank, A., Seibert, P., and Wotawa, G.: Technical note: The Lagrangian particle dispersion model FLEXPART version 6.2., Atmos. Chem. Phys., 5, 2461-2474, doi:10.5194/acp-5-2461-2005, 2005.

Stohl, A., Seibert, P., Arduini, J., Eckhardt, S., Fraser, P., et al.: An analytical inversion method for determining regional and global emissions of greenhouse gases: Sensitivity studies and application to halocarbons, Atmos. Chem. Phys., 9, 1597-1620, doi:10.5194/acp-9-1597-2009, 2009.

Stohl, A., Prata, A. J., Eckhardt, S., Clarisse, L., Durant, A., Henne, S., Kristiansen, N. I., Minikin, A., Schumann, U., Seibert, P., Stebel, K., Thomas, H. E., Thorsteinsson, T., Trseth, K., and Weinzierl, B.: Determination of time- and height-resolved volcanic ash emissions and their use for quantitative ash dispersion modeling: the 2010 Eyjafjallajökull eruption, Atmos. Chem. Phys., 11, 4333-4351, doi:10.5194/acp-11-4333-2011, $2011 \mathrm{a}$.

Stohl, A. et al.: Interactive comment on "Xenon-133 and caesium137 releases into the atmosphere from the Fukushima Dai-ichi nuclear power plant: determination of the source term, atmospheric dispersion, and deposition" by A. Stohl et al., Atmos. Chem. Phys. Discuss., 11, C12298-C12304, 2011.

Stohl, A., Seibert, P., and Wotawa, G.: Total emissions of Xenon133 from the Fukushima Dai-ichi nuclear power plant constrained by measured atmospheric concentrations, Geophys. Res. Lett., in preparation, 2012.

United Nations Scientific Committee on the Effects of Atomic Radiation (UNSCEAR): Annex C: Exposures to the public from man-made sources of radiation, in Sources and Effects of Ionizing Radiation, vol. 1, Sources, Report to the Gen. Assem., 291 pp., Vienna, Austria, 2000a.

United Nations Scientific Committee on the Effects of Atomic Radiation (UNSCEAR): Annex J: Exposures and effects of the Chernobyl accident, in Sources and Effects of Ionizing Radiation, vol. 2, Effects, Report to the Gen. Assem., 115 pp., Vienna, Austria, 2000 b.

USGS (United States Geological Service): List of significant earthquakes. Magnitude 9.0 - NEAR THE EAST COAST OF HONSHU, JAPAN, 2011 March 11 05:46:23 UTC, http://earthquake.usgs.gov/earthquakes/eqinthenews/2011/ usc0001xgp/, Retrieved 30 July 2011.

Vallés, I., Camacho, A., Ortega, X., Serrano, I., Blázquez, S., Pérez, S.: Natural and anthropogenic radionuclides in airborne particulate samples collected in Barcelona (Spain), J. Environ. Radioact., 100, 102-107, 2009.

Wernli, H., and Davies, H. C.: A Lagrangian-based analysis of extratropical cyclones, I, The method and some applications, Q. J. Roy. Meteor. Soc., 123, 467-489, 1997.

Wernsberger, B., and Schlosser, C.: Noble gas monitoring within the international monitoring system of the Comprehensive $\mathrm{Nu}$ clear Test-Ban Treaty, Radiation Phys. Chem., 71, 775-779, 2004.

Wotawa, G., Becker, A., Kalinowski, M., Saey, P., Tuma, M., and 
Zähringer, M.: Computation and analysis of the global distribution of the radioxenon isotope ${ }^{133} 133$ based on emissions from nuclear power plants and radioisotope production faclities and its relevance for the verification of the Nuclear-Test-Ban treaty, Pure Appl. Geophys., 167, 541-557, 2010

Winiarek, V., Bocquet, M., Saunier, O., and Mathieu, A.: Estimation of errors in the inverse modeling of accidental release of atmospheric pollutant: application to the reconstruction of the cesium-137 and iodine-131 source terms from the Fukushima Daiichi power plant, J. Geophys. Res., doi:10.1029/2011JD016932, in press, 2012.
Yamauchi, M.: Secondary wind transport of radioactive materials after the Fukushima accident, Submitted to Earth, Planets and Space, 2012.

Yasunari, T., Stohl, A., Hayano, R. S., Burkhart, J. F., Eckhardt, S., and Yasunari, T.: Cesium-137 deposition and contamination of Japanese soils due to the Fukushima nuclear accident, Proc. Natl. Acad. Sci., 108, 19530-19534, doi:10.1073/pnas.1112058108, 2011. 